\title{
PRESENÇA CLÍNICA E ANGULAÇÃO DOS TERCEIROS MOLARES SUPERIORES, NA MÁ OCLUSÃO DE CLASSE \\ II, TRATADA SEM E COM EXTRAÇÕES DE PRÉ- MOLARES SUPERIORES.
}

\section{LAÉLIA MARIA PUTRICK}

Dissertação apresentada à Faculdade de Odontologia de Bauru da Universidade de São Paulo, como parte dos requisitos para a obtenção do título de Mestre em Odontologia, área de Ortodontia.

(Edição Revisada)

\section{BAURU}




\title{
PRESENÇA CLÍNICA E ANGULAÇÃO DOS TERCEIROS MOLARES SUPERIORES, NA MÁ OCLUSÃO DE CLASSE \\ II, TRATADA SEM E COM EXTRAÇÕES DE PRÉ- MOLARES SUPERIORES.
}

\section{LAÉLIA MARIA PUTRICK}

\author{
Dissertação apresentada à Faculdade \\ de Odontologia de Bauru da \\ Universidade de São Paulo, como \\ parte dos requisitos para a obtenção \\ do título de Mestre em Odontologia, \\ área de Ortodontia.
}

(Edição Revisada)

Orientador: Prof. Dr. Guilherme dos

Reis Pereira Janson

\section{BAURU}




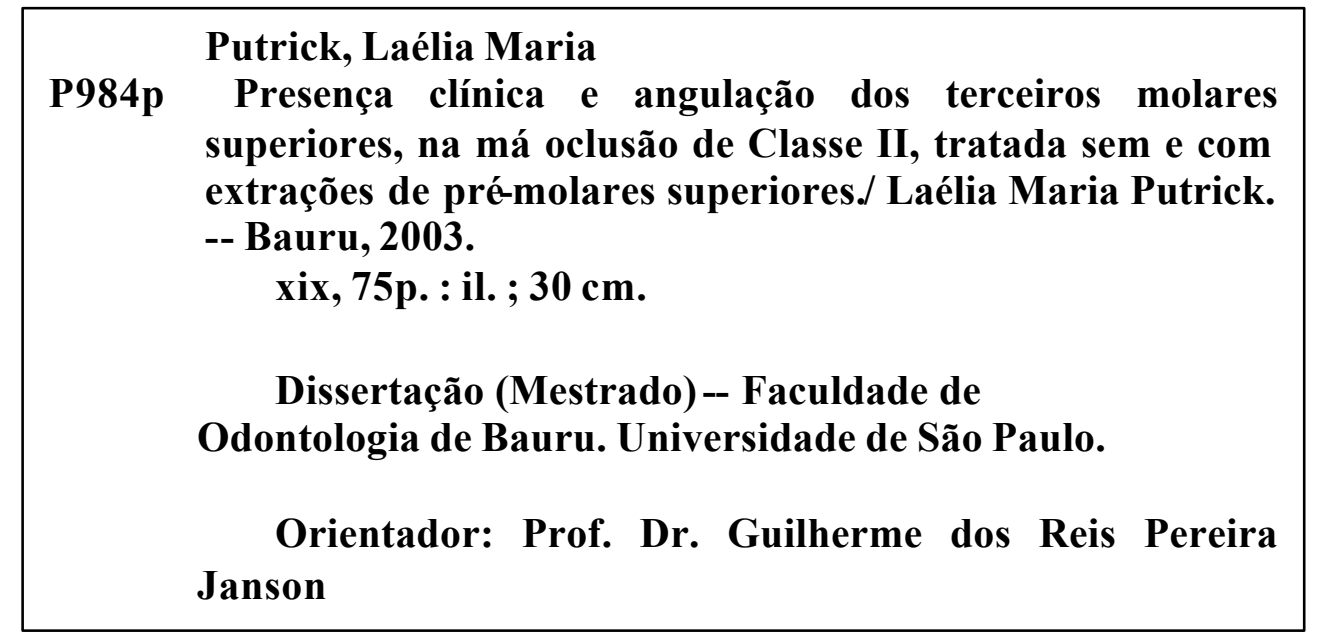

Autorizo, exclusivamente para fins acadêmicos e científicos, a reprodução total ou parcial desta dissertação/tese, por processos fotocopiadores e outros meios eletrônicos.

Assinatura:

Data:

Comitê de Ética da FOB: Projeto de pesquisa aprovado em 24 de abril de 2002

No do Protocolo: ODON-2042002 


\section{DADOS CURRICULARES}

\section{LAÉLIA MARIA PUTRICK}

13 de junho de 1961

Planalto - RS

Filiação

$1980-1984$

2002

$2002-2003$

Associação
Nascimento

Claudino Putrick (in memorian)

Ofélia Calgaro Putrick

Curso de Graduação em Odontologia, na Universidade Federal de Santa Maria RS

Curso de Especialização em Ortodontia pela Associação Paulista de CirurgiõesDentistas - APCD - Presidente Prudente $-\mathrm{SP}$.

Curso de Pós-Graduação em nivel de Mestrado em Ortodontia, no Mestrado Interinstitucional - FOB /USP - UEL, UEM e demais associadas.

APCD - Associação Paulista de Cirurgiões-Dentistas. 
Dedicatóría 


\section{DEDICO ESTE TRABALHO}

A Deus, que está acima de todas as coisas.

Á minha filha Camila, por tudo que representa e pela emoção de estarmos crescendo juntas.

Ao meu marido Clóvis, meu companheiro e amigo, que em todos os momentos está ao meu lado me fortalecendo e mostrando a cada dia o brilho da felicidade. Sua cumplicidade, compreensão, paciência e carinho, foram decisivos para a finalização deste trabalho.

Aos meus pais, Ofélia e Claudino (in memorian), por toda a eternidade e por tudo que me proporcionaram na vida. Á eles dedico este trabalho, lembrando-me sempre do exemplo, da força e garra por eles demonstradas e que são necessárias para vencer obstáculos e alcançar objetivos. Espero estar sempre podendo retribuir.

Ás minhas irmãs, Lilia e Leomar por nossa união e eterna amizade. 


\section{Ao Prof: Dr. Guilherme Janson,}

meu orientador e coordenador do curso de Pós-Graduação em Ortodontia da FOB - USP, ao nivel de Mestrado, agradeço os ensinamentos transmitidos, as criticas positivamente dirigidas e a credibilidade em mim depositada. Agradeço também por sempre ter me

impulsionado á realização de atividades que me fizeram crescer cientificamente. Por preocupar-se com a veracidade dos dados obtidos e utilizados neste trabalho, mostrando qualidade e seriedade nas pesquisas em que é orientador. 


\title{
Ao Prof. Dr. José Fernando Castanha Henriques,
}

Professor Titular, Coordenador do Curso de Pós-

Graduação em Ortodontia, ao nivel de Doutorado, pelo incentivo profissional, pelas orientações e ensinamentos transmitidos, pelo incentivo e apoio ao magistério. Meus sinceros agradecimentos.

Ao Prof. Dr. Marcos Roberto de Freitas, minha eterna gratidão pelos primordias e inestimáveis ensinamentos transmitidos.

\author{
À Profa Dra Maria Fidela de Lima Navaro, \\ coordenadora acadêmica do mestrado interinstitucional $e$ \\ diretora da Faculdade de Odontologia de Bauru, por toda \\ sua dedicação e empenho, \\ minha eterna gratidão.
}

Ao Prof. Dr. Newton Expedito de Moraes, coordenador operacional do mestrado interinstitucional, pela sua amizade e carinho, meu muito obrigada de coração. 
Agradecimentos 


\section{AGRADECIMENTOS}

À Faculdade de Odontologia de Bauru (FOB - USP) e à Comissão de Pós-Graduação na pessoa do Prof. Dr. José Carlos Pereira,

Aos amigos e colegas do curso de mestrado na área de Ortodontia, Carlos Alberto G. Cabrera, Carlos Eduardo de Oliveira Lima, Fábio Rogério T. Maria, João Tadeu A Graciano, Marcos Antônio Cirino dos Santos, Marise de Castro Cabrera, Mauro Carlos Agner Busato, Nadyr Maria Virmond Alcazar e Ricardo Fernando Zampieri pela amizade presente em momentos por nós partilhados.

Aos amigos e colegas de outras áreas do mestrado, professores da Unioeste, Virginia, Geraldo, Rolando, Elizeu, Denise, Maria de Fátima e Clóvis pela amizade, união, entusiasmo e confiança sempre presente em todos os momentos por nós compartilhados.

Aos funcionários da Disciplina de Ortodontia da FOB-USP, Cristina, Sérgio, Vera e "Tia" Maria pela dedicação, carinho e atenção com que sempre me atenderam. 
Ao Prof. José Roberto Lauris pela paciência e orientação no treinamento estatístico deste trabalho.

Aos funcionários da Biblioteca pela paciência $e$ dedicação na Revisão Bibliográfica deste trabalho.

A todos os pacientes pertencentes a esta amostra, fundamentais para a minha formação profissional.

Ao meu amigo Rony, pela paciência, apoio $e$ grande ajuda nos trabalhos de informática.

Aos meus alunos de Odontologia da Unioeste, pela compreensão nos momentos da minha ausência.

Ao Coordenação de Aperfeiçoamento de Pessoal de Nivel Superior - CAPES, pelo apoio financeiro para a realização do curso e viabilização deste projeto.

A todos que direta ou indiretamente estiveram envolvidos no desenvolvimento deste trabalho. 
Sumárío 


\section{SUMÁRIO}

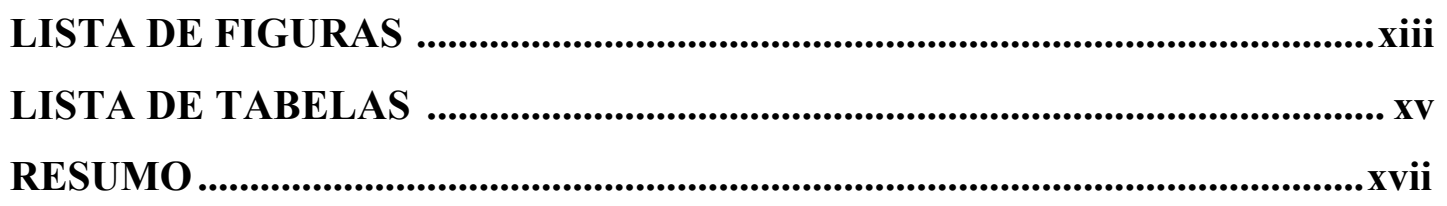

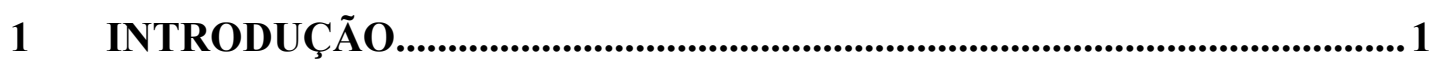

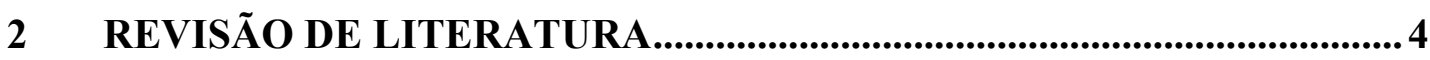

2.1 Crescimento e desenvolvimento ósseo .................................................... 5

2.2 Época e evolução do irrompimento dos terceiros molares superiores............ 8

2.3 Impacção dos terceiros molares superiores .............................................. 15

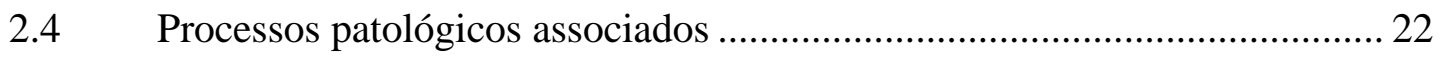

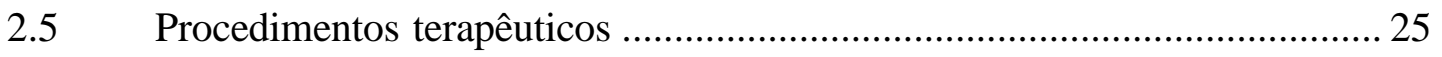

2.6 Terceiros molares e extrações de dentes permanentes ............................... 28

3 PROPOSIÇÃ̃O

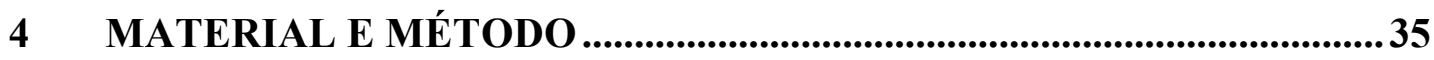

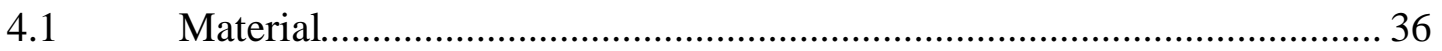

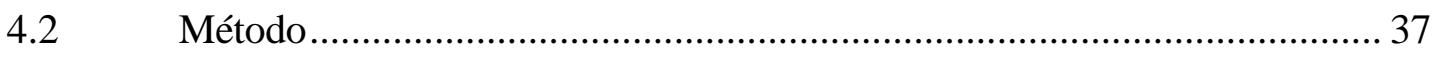

4.2.1 Avaliação da presença dos terceiros molares superiores irrompidos

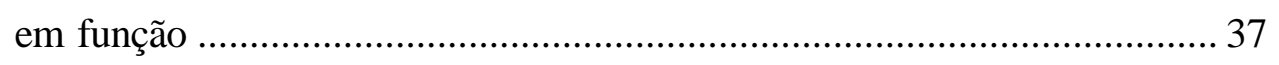

4.2.2 Avaliação das angulações mesiodistais do terceiros

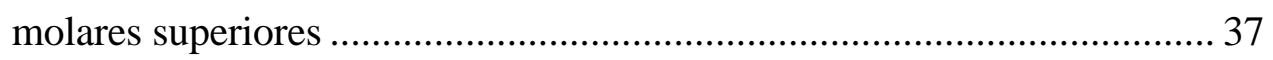

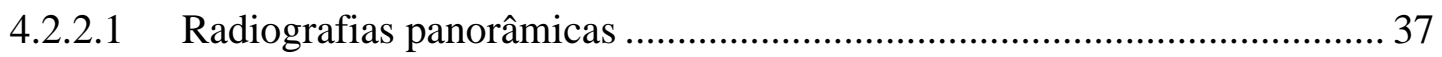

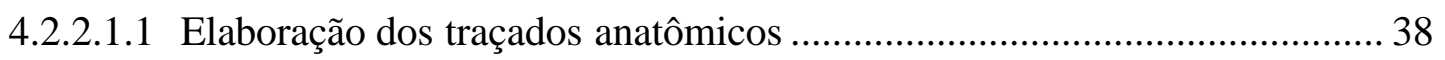

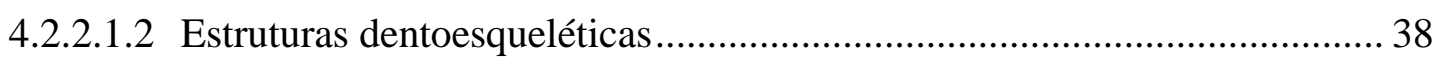

4.2.2.1.3 Demarcação dos pontos e traçado das linhas de referência..................... 39

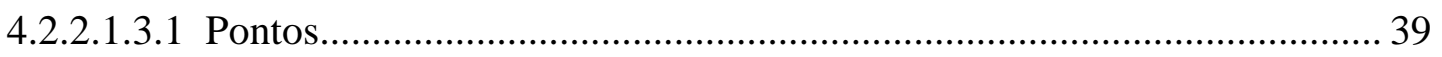




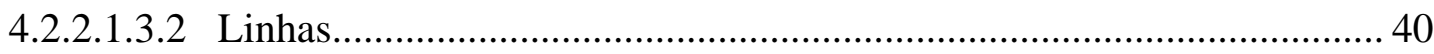

4.2.2.1.4 Mensuração dos ângulos ...................................................................... 40

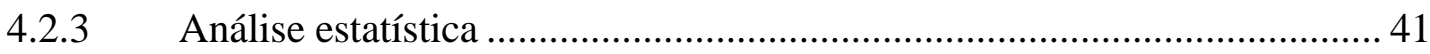

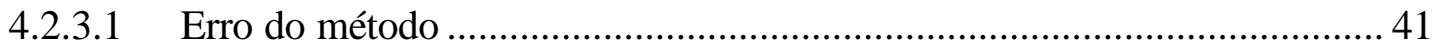

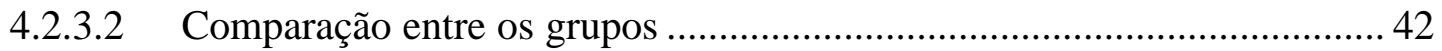

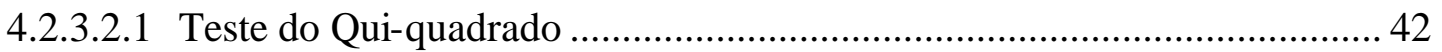

4.2.3.2.2 Teste t para variáveis independentes ....................................................... 42

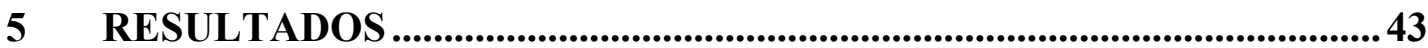

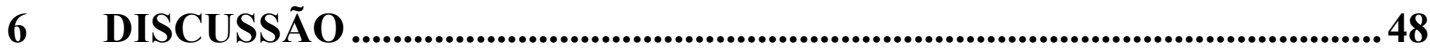

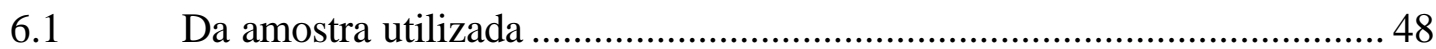

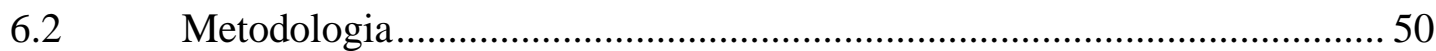

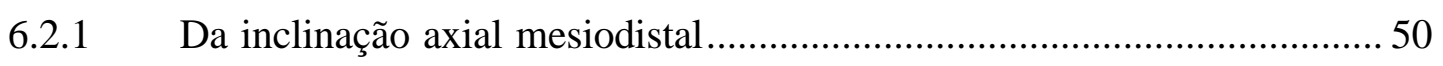

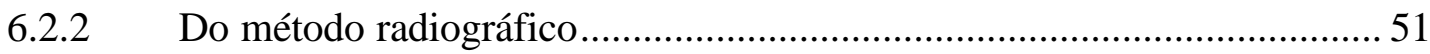

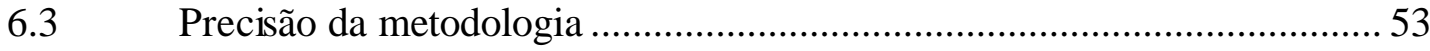

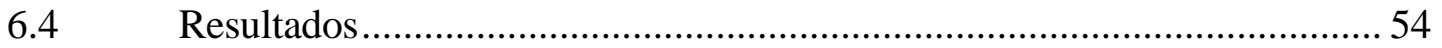

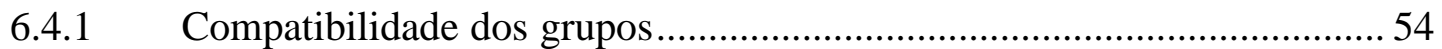

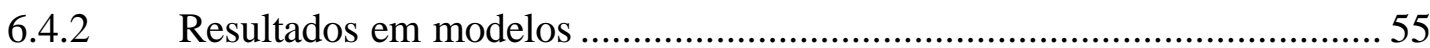

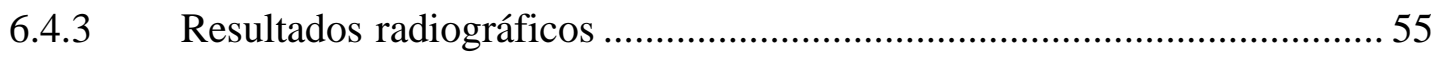

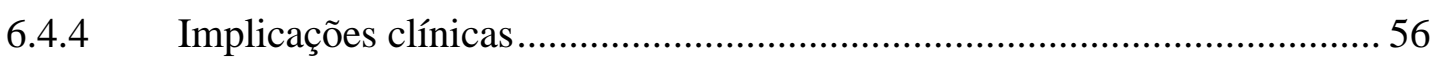

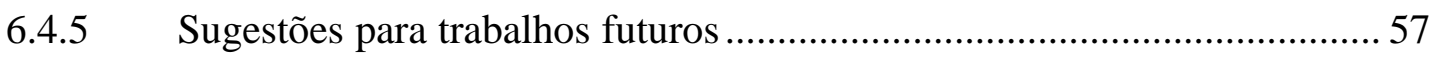

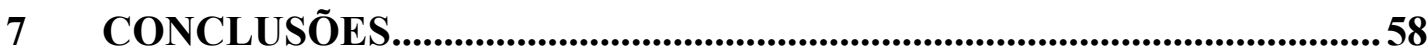

REFERÊNCIAS BIBLIOGRÁFICAS ............................................................60

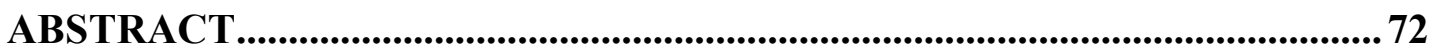

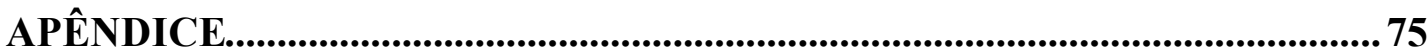


Lista de Figuras 


\section{LISTA DE FIGURAS}

FIGURA 1 - Reparos anatômicos.

FIGURA 2 - Ângulos formados pelos longos eixos dos dentes superiores e a linha interorbital e longos eixos dos dentes superiores e a linha intertuberosidade 40 
Lista de Tabelas 


\section{LISTA DE TABELAS}

TABELA 1 - Apresentação dos erros casuais (dahlberg) e dos resultados do teste $t$ para amostras dependentes, do teste intra-examinador. . .44

TABELA 2 - Teste do qui-quadrado .........................................................................45

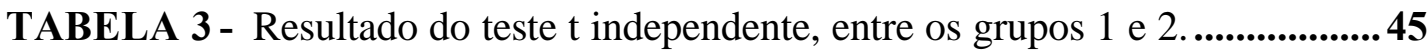




\section{RESUMO}

Este trabalho objetivou comparar o número presente de terceiros molares superiores, em função, entre pacientes com Classe II, tratados ortodonticamente, sem e com extrações de dois pré-molares superiores. Para tanto, foram selecionados 55 documentações de pacientes, divididos em dois grupos. O grupo 1, tratado sem extrações, foi constituído de 28 pacientes, com idade média de 19,03 anos (idade mínima de 14,08 anos e máxima de 23,92 anos) e o grupo 2, tratado com extrações, foi composto de 27 pacientes, com idade média de 19,94 anos (idade mínima de 14,75 anos e máxima de 25,67 anos). Para verificação do irrompimento em oclusão dos terceiros molares, utilizou-se modelos de gesso superior e inferior do último controle dos grupos tratados ortodonticamente. Adicionalmente realizoutse avaliações das angulações axiais mesiodistais dos terceiros molares superiores utilizando radiografias ortopantomográficas do último controle com a presença dos terceiros molares superiores bilateralmente. As angulações axiais dos terceiros molares foram medidas em relação as órbitas e as tuberosidades, em ambos grupos e foram comparadas. Para comparar o número de terceiros molares superiores irrompidos e em função em ambos os grupos, foi utilizado o teste do Qui-quadrado e para comparar as angulações dos terceiros molares entre os grupos, foi utilizado o teste $\mathrm{t}$ independente. Os resultados demonstraram que a quantidade de terceiros molares superiores irrompidos e em função foi estatisticamente maior nos casos tratados com extrações dos pré-molares superiores em relação aos casos tratados sem extrações e as angulações mesiodistais foram estatisticamente menores e mais favoráveis ao irrompimento dos mesmos, 
respectivamente. Portanto, pode-se esperar que o resultado do posicionamento dos terceiros molares superiores na má oclusão de Classe II, quando conduzido com extrações de dois pré-molares, sejam melhores do que quando realizado sem extrações de dois pré-molares superiores. 
Introdução 


\section{INTRODUÇÃO}

Sabe-se que, de acordo com a teoria da evolução, os terceiros molares estão tendendo a desaparecer do conjunto de dentes da raça humana. Por esse motivo, são eles que estão mais propensos a se tornar impactados na fase atual da evolução. ROTHEMBERG ${ }^{74}$ em 1945. Não é incomum se encontrar terceiros molares impactados em pacientes ortodônticos tratados com extrações de prémolares. No entanto, a incidência de impacção de terceiros molares parece ser menor entre esses pacientes do que na população em geral, HAAVIKKO, ALTONEN e MATTILA $^{33}$ em 1978. A explicação para esse fato é que casos tratados com extrações de pré-molares permitem a mesialização do primeiro molar, que consequentemente cria mais espaço na região de terceiros molares. Entretanto, a relação entre a extração de pré-molares superiores e a impacção dos terceiros molares não tem sido ainda extensivamente estudada.

O tratamento de pacientes com má oclusão de Classe II, sem discrepância cefalométrica ou com uma quantidade mínima de apinhamento, durante a fase de crescimento, geralmente consiste em se distalizar os dentes superiores ou se recorrer a extrações de dois pré-molares superiores para a correção do problema. A primeira opção depende enormemente da colaboração do paciente em utilizar aparelhos extrabucais para a distalização dos dentes superiores e portanto é mais susceptível ao insucesso. A segunda opção, também requer a colaboração do paciente, entretanto, num grau bem menor. Portanto, é mais propensa a proporcionar uma maior porcentagem de sucesso do tratamento. Contudo, como requer a extração 
de dois pré-molares superiores, pode encontrar algum obstáculo dos pais dos pacientes em aceitá-las. Como mencionado acima, especula-se que esses casos teriam uma maior probabilidade de apresentarem os terceiros molares irrompidos do que os casos tratados sem extrações. Portanto, com a intenção de se investigar essa especulação decidiu-se comparar a presença e a angulação dos terceiros molares superiores em casos tratados sem e com extrações dos pré-molares superiores. 
Revisão de Literatura 


\section{REVISÃO DE LITERATURA}

Objetivando uma melhor compreensão, a revisão de literatura foi desenvolvida de forma a fornecer informações quanto ao espaço disponível para o irrompimento dos terceiros molares superiores em pacientes Classe II com e sem extrações de pré-molares superiores. Abordoutse também o crescimento e desenvolvimento ósseo dos maxilares, a época e a evolução do irrrompimento dos terceiros molares superiores, as complicações decorrentes da impacção dos terceiros molares superiores, os processos patológicos associados, os procedimentos terapêuticos e extrações de outros dentes permanentes.

\subsection{Crescimento e desenvolvimento ósseo}

Nas arcadas primitivas, encontram-se constantemente, os terceiros molares em atrição, o que indica que os arcos dentais são grandes, suficientemente, para que os dentes tomem parte ativa na mastigação.

Em 1930, GOBLIRSCH ${ }^{28}$ estudando terceiros molares, considerou que se o crescimento dos maxilares for deficiente, não haverá espaço suficiente para o desenvolvimento e erupção destes dentes.

Para os autores HENRY; MORANT ${ }^{36}$, em 1936, os tipos primitivos possuíam amplo espaço para o alinhamento dos terceiros molares superiores e inferiores com os outros dentes e haveria, freqüentemente, espaços 
distais aos mesmos. Nos tipos com menos desenvolvimento dos ossos, as tuberosidades eram menores. Poderia não haver grandes irregularidades nos dentes anteriores, mas poderia existir restrições de espaço na região posterior. Verificaram que o tamanho dos dentes é determinado no indivíduo bem antes de cessar o crescimento das arcadas.

BROADBENT $^{10}$, em 1943, correlacionou o desenvolvimento facial normal e o irrompimento dos terceiros molares. Assim sendo, com o crescimento normal da face, haveria espaço suficiente para o irrompimento de todos os dentes em posições adequadas nas arcadas. Quando da época de irrompimento dos dentes permanentes, se os ossos de suporte não estivessem harmônicos com eles, haveria uma tendência a assumir a posição que ocupavam quando o osso estava em um estágio mais jovem. Assim, o retardamento no processo de desenvolvimento dos ossos de suporte está diretamente ligado ao grau de mal oclusão e más posições dentárias. A face das pessoas com três ou quatro terceiros molares impactados, são menores em todos os sentidos, que das pessoas que os possuem em oclusão e também apresentam a dimensão vertical diminuída.

ROTHEMBERG $^{74}$, em 1945, prognostica o futuro desaparecimento dos terceiros molares. Entende que a redução do tamanho dos dentes se produz em função da diminuição do trabalho mastigatório.

FIGUN; GARINO 22 , em 1986, relataram que a diminuição do uso da força mastigatória causa, entre outras consequiências, a redução gradual do tamanho das maxilas e da mandíbula. Esta redução não foi acompanhada, na mesma intensidade pela diminuição do número de dentes. 
ADES, et al $^{1}$, em 1990, não encontraram diferenças significativas no crescimento ósseo entre os grupos estudados (impactados, irrompidos em função, congenitamente ausentes e extraídos 10 anos após a contenção), sugerindo que pacientes, com terceiros molares irrompidos, não apresentaram padrão de crescimento ósseo diferente em relação aos demais grupos.

Grupos de pessoas com ausência de terceiros molares, quando comparados a pessoas portadoras destes dentes, mostram diferenças em todas as dimensões, PAIVA ${ }^{60}$, em 1990.

Para ENLOW ${ }^{19}$, em 1993, a posição da maxila depende do crescimento ao nível das sincondroses esfeno-occipital e esfeno-etmoidal. O crescimento da maxila faz-se através da proliferação do tecido conjuntivo sutural, ossificação intramembranosa, aposição óssea superficial, reabsorção e translação. Há uma direção predominante de crescimento para trás e para cima, que faz com que a maxila se desloque para frente e para baixo. Na tuberosidade dos maxilares superiores ocorre aposição óssea, que concorre para aumentar o comprimento do processo alveolar.

O crescimento vertical está intimamente relacionado com o crescimento das órbitas e das fossas nasais. A reabsorção na face superior dos processos palatinos (assoalho das fossas nasais) juntamente com a aposição na face inferior (palato duro), promove um "deslizamento" do assoalho das fossas nasais. Simultaneamente, crescem os processos frontal e zigomático dos maxilares superiores, bem como o septo nasal. O crescimento, em altura do processo alveolar, está relacionado com o desenvolvimento e erupção dos dentes. 


\section{2 Época e evolução do irrompimento dos terceiros molares superiores}

De acordo com BROADBENT ${ }^{10}$, em 1943, quando da época do irrompimento dos dentes permanentes, se os ossos de suporte não estiverem harmônicos com eles, haveria uma tendência a assumir a posição que ocupavam quando osso estava num estágio mais jovem. Assim o retardamento no processo de desenvolvimento dos ossos de suporte está, diretamente, ligado ao grau de mal oclusão. Acreditou também que importantes mudanças na inclinação axial dos terceiros molares superiores se faz entre as idades de 16 aos 18 anos de idade, onde as raízes destes dentes movem-se, abruptamente para a frente, no osso.

SICHER $^{77}$, em 1947 observa que, se atentarmos para a tendência característica na evolução da dentição humana, tanto quanto está documentada pelos achados de fósseis hominídeos, pode-se apontar a redução progressiva do aparelho mastigatório. Este processo parece que não chegou ao seu término. A ausência de um ou mais, ou de todos os terceiros molares podem ser interpretadas como mutações para a redução da dentição humana.

Também STRANG ${ }^{82}$, em 1950, observou que o início da calcificação dos terceiros molares superiores ocorre entre os 7 e 9 anos de idade, terminando aproximadamente, um a dois anos após o início do irrompimento. Em média após os 17 anos de idade.

Para NANDA ${ }^{56}$, em 1954, estudou 216 jovens mulheres brancas americanas com idade média de 18 a 21 anos e observou que os terceiros molares apresentavam grande variações morfológicas e, freqüentemente, apresentavam falhas 
no desenvolvimento de seus orgãos formativos, resultando em ausência completa de um ou mais dentes.

Segundo GARN; LEWIS; BONNÉ ${ }^{25}$, em 1962, sustentaram a observação de que o terceiro molar é o último dente da série molar e que a redução, no segmento distal da série de incisivos e pré-molares, poderia ser antecipada, caso ocorresse sua ausência. Nesta linha de pensamento, as reduções no número de dentes nunca deveria ser considerada separadamente, mas sempre em relação a presença ou a ausência do terceiro molar. No mesmo ano, os autores, verificaram a grande variação nas idades para cada estágio de formação e de movimentação do dente. Relataram que o terceiro molar seria refratário ás influências que aceleram o desenvolvimento físico. As inter-relações com seu crescimento corporal e com a maturação sexual seriam baixas e, raramente significantes, enfatizando a autonomia de desenvolvimento destes dentes. Afirmaram, também, que a época de formação dos terceiros molares que guiará seu processo de irrompimento, ou seja, uma mineralização tardia destes dentes vem acompanhada de um irrompimento tardio, assim como aqueles que iniciam o processo de calcificação mais cedo atingem a maturidade de sua formação, precocemente. Tal fato não indica, necessariamente, que o irrompimento dos terceiros molares superiores venha a ser normal, pois, com relativa freqüência, os dentes podem se tornar impactados. Desta maneira, foi também associado o irrompimento ou impacção dos terceiros molares a uma herança genética.

Em 1962, GARN; LEWIS; BONNÉ25 identificou um total de nove estágios de calcificação e movimento de irrompimento dos terceiros molares: 1) 
folículo inicial ou cripta do terceiro molar; 2) folículo completo; 3) calcificação das cúspides; 4) formação completa da coroa; 5) início da formação radicular; 6) metade da raiz completa; 7) irrompimento alveolar; 8) irrompimento na cavidade bucal e 9) fechamento dos ápices. O autor afirmou serem os terceiros molares inteiramente compatíveis com seu desenvolvimento, ou seja, a época de formação é que guiará seu irrompimento. Desta forma, uma mineralização tardia destes dentes é acompanhado de um irrompimento também tardio, assim como, aqueles que iniciam o processo de calcificação mais cedo, atingiram a maturidade de formação precocemente. Tal fato não indica, necessariamente, que o irrompimento dos terceiros molares venha a ser normal, pois , com relativa freqüência, os dentes podem se tornar impactados. Desta maneira, foi também associada o irrompimento ou impacção dos terceiros molares a uma base genética.

Estudando minuciosamente os terceiros molares GARN et $\mathrm{al}^{26}$, em 1963, observaram que as agenesias dos terceiros molares estão relacionados com as agenesias de outros dentes, a calcificação atrasada de outros dentes posteriores, as diferentes seqüências de desenvolvimento e com os dentes menores em outras partes da boca. No homem, há tendências evolutivas para perder os dentes e ter os maxilares menores, porém estas duas tendências parecem não estar correlacionadas.

$\mathrm{KEENE}^{43}$, em 1964, verificou que as ausências congênitas dos terceiros molares não seriam anomalias, completamente, isoladas. Em seu estudo, encontrou $25 \%$ dos indivíduos com ausências de um ou mais molares e com pouco apinhamento. 
Os estudos concernentes ao irrompimento e a impacção dos terceiros molares, bem como as modificações que estes dentes podem imprimir nos arcos dentários, durante o processo de irrompimento, advêm de longa data. Os remotos registros de Hipócrates e Aristóteles assinalam que o irrompimento dos terceiros molares ocorre próximo a idade adulta dos indivíduos. Por esta razão, estes dentes foram denominados "dens sapentiae" por irromperem numa idade, na qual espera-se amadurecimento da personalidade, demonstrando através das manifestações comportamentais dos indivíduos RANTANEN ${ }^{64}$, em 1967.

Estudando as diferentes épocas da formação dos terceiros molares, RICHARDSON $^{67}$, em 1980, investigou dois grupos de trinta e cinco crianças, com quatorze do sexo masculino e vinte e um do sexo feminino. O primeiro grupo não apresentou, aos dez anos de idade, qualquer evidência radiográfica da formação dos terceiros molares. Foi considerado como grupo tardio, já que a idade máxima para a formação das criptas foi estabelecida aos sete anos. O segundo grupo, considerado precoce, apresentou indícios de formação dos terceiros molares antes dos dez anos de idade. Anualmente foram tiradas radiografias cefalométricas laterais de $60^{\circ}$, dos lados direito e esquerdo de todos os indivíduos pesquisados. Embora a gênese de terceiros molares acima dos doze anos de idade fosse pouco freqüente, foram encontrados casos em que a formação se dava acima dos dezesseis anos de idade. Quando os terceiros molares não iniciaram sua formação até os dez anos de idade, a possibilidade de seu desenvolvimento ficou diminuída em $50 \%$.

Na mesma época, RICHARDSON ${ }^{67}$, em 1980, verificou que, se além dos 10 anos de idade não se observar radiograficamente evidência da formação 
dos terceiros molares, a probabilidade de desenvolvimento desses dentes é reduzida em 50\%, aproximadamente.

Em 1980, MOYERS ${ }^{55}$ afirma que os terceiros molares mostram mais variabilidade na calcificação e erupção do que quaisquer outros dentes. Os terceiros molares são os únicos entre os dentes humanos, pois aparentemente eles não apresentam diferenças sexuais na formação, nem está relacionado tão diretamente com o crescimento somático e maturação sexual como estão os outros dentes. Por outro lado, o terceiro molar apresenta uma elevada constância com seu próprio padrão de desenvolvimento; isto é, terceiros molares calcificados irrompem cedo e completam suas raízes precocemente. Suas pesquisas se referem a várias teorias sobre "campos genéticos" que produzem iquais tamanhos, formatos e posições, durante o desenvolvimento. Existem inclinações sobrepostas que produzem padrões de similaridade de um dente com seus antímeros do lado oposto do mesmo arco, seu antímero funcional no arco oposto e outros dentes em seu próprio quadrante. As correlações de tamanho nos lados direito e esquerdo são extremamente elevados para os dentes individuais (média $\mathrm{r}=0.9$ ) e ainda mais elevados se todos os dentes em um quadrante foram somados. Em nenhum lugar do corpo a simetria é tão rigorosamente bem definida. As correlações de tamanho superior e inferior são também elevadas (média $\mathrm{r}=0.7$ ). De um modo geral, quanto mais mesiais estão os dentes dentro de cada grupo de cada quadrante, menor variabilidade mostram no desenvolvimento e no tamanho. O dente mais distal dentro de cada grupo manifesta a maior variabilidade no tamanho, é o que mais está apto a ser congenitamente perdido e é mais freqüentemente anormal em forma e a sua época de calcificação é típica, como por exemplo os terceiros molares. 
GRABER; KAINEG ${ }^{31}$, em 1981, observaram que a mineralização do terceiro molar superior são mais avançadas em indivíduos que tiveram estes dentes irrompidos, comparados com os que apresentaram impacção.

ENGSTRÖM et al. ${ }^{18}$, em 1983, pesquisaram longitudinalmente os estágios de desenvolvimento dos terceiros molares em duzentos e vinte e um indivíduos, sendo cento e vinte três do sexo feminino e oitenta e oito do sexo masculino, relacionados á maturação esquelética, através da mineralização das epífises da mão. Forte correlação foi encontrada entre o desenvolvimento dentário, e maturação óssea e a idade cronológica. Um ou dois terceiros molares estavam ausentes em $11 \%$ dos casos estudados.

RICHARDSON; MALHOTRA; SEMENYA ${ }^{69}$, em 1984, sustentaram a possibilidade de que algumas estruturas como músculos e rafe ptérigomandibular pudessem ser fatores de impacção destes dentes. As extrações de prémolares tem sido justificadas como a criação de espaço para o irrompimento dos terceiros molares.

Em 1985, COHE et al. ${ }^{13}$ fizeram estudos longitudinais mostrando que a angulação dos terceiros molares diminui com a idade.

Para MOYERS ${ }^{55}$, em 1988, a agenesia do terceiro molar ocorre em média em $16 \%$ dos pacientes. Quando um ou mais terceiros molares estão ausentes, há uma forte tendência para a agenesia de outros dentes, formação retardada de outros dentes posteriores, diferenças na seqüência de desenvolvimento, redução no tamanho de outros dentes, e cronologia e movimento eruptivo tardio do terceiro molar. Se os primeiros molares superiores são movidos distalmente, reduziria o 
espaço disponível para o irrompimento dos terceiros molares superiores. Como regra geral é necessário $18 \mathrm{~mm}$ entre a distal do primeiro molar e a PTV para que ocorra um bom irrompimento dos terceiros molares superiores. Se menos espaço é esperado, o prognóstico é desfavorável, causando relapso e desordens temporomandibular. No entanto o espaço disponível é alterado pelo tratamento ortodôntico e não podemos fazer predições até que o tratamento seja concluído. A questão do papel do terceiro molar no apinhamento dos incisivos inferiores durante o último período da adolescência, tem sido muito estudada. Uma série de fenômenos simultâneos confundem o assunto: o perímetro do arco encurta, o apinhamento dos incisivos aumenta, os terceiros molares se desenvolvem e a mandíbula cresce mais para a frente do que a maxila. Os acontecimentos que ocorrem junto não dependem, necessariamente um do outro. Relaciona-se melhor o apinhamento do incisivo com o desenvolvimento mandibular do que com a erupção dos terceiros molares. Observout se que os primeiros molares se posicionavam mais para a frente e os incisivos eram mais projetados em indivíduos com terceiros molares do que naqueles com agenesia dos terceiros molares. Por tanto, os terceiros molares não podem desempenhar um papel principal na posição de quaisquer dentes mesiais, pois as diferenças na posição do primeiro molar e a projeção dos dentes anteriores incisais aparecem antes do desenvolvimento significativo do terceiro molar. A evidência favorece a absolvição do terceiro molar do apinhamento crescente.

Os autores STAGGERS; GERMANE; FORSTON ${ }^{79}$, em 1992, verificaram que o tratamento ortodôntico não apresentou diferenças significativas na angulação dos terceiros molares, entre os grupos com e sem extrações. A angulação melhorou ainda que o método de tratamento fosse diferente. No entanto, a melhora 
na angulação não significaria, necessariamente, que os terceiros molares iriam irromper em boas condições, concluíram então que outros fatores, além das extrações, causam influências na angulação e no irrompimento destes dentes.

\subsection{Impacção dos terceiros molares superiores}

Segundo HELLMAN ${ }^{34}$, em 1936, haveria diminuição no tamanho da maxila e da mandíbula, com conseqüente redução de espaço para acomodação de todos os dentes. Como os terceiros molares seriam os últimos dentes a irromperem e a completarem a dentição permanente, haveria, ás vezes, complicações que atrapalhariam a sequiência favorável ao irrompimento. Conseqüentemente estes dentes poderiam ficar atrasados no seu aparecimento na cavidade bucal, ficar retidos ou não se formarem.

Para HENRY; MORANT ${ }^{36}$, em 1936, a impacção teria, como causa primária, a falha do osso em crescer o suficiente, para permitir que o último dente a irromper assumisse sua posição na dentição adulta.

A impacção dos terceiros molares parece estar intimamente associada a distúrbios de desenvolvimento da face que, por sua vez, depende parcialmente do tipo de alimentação do homem moderno, pois a preparação artificial dos alimentos determina redução da atividade funcional mastigatória (HELLMAN ${ }^{35}$ 1938; FORD ${ }^{23}$ 1940). 
Pesquisando quatrocentos e oitenta indivíduos do sexo masculino, BJÖRK em 1956, também considerou a falta de espaço como a causa essencial para a impacção dos dentes. HILLIN, em 1947, pesquisou e obteve a mesma constatação.

BJÖRK ${ }^{8}$, em 1956, demonstrou que, medindo o espaço disponível em um raio-x cefalométrico, a distância entre a borda anterior do ramo e do segundo molar, a probabilidade de impacção decresce quanto mais espaço tem disponível. Usando 100 crânios de índios, tomando como regra que a probabilidade de irrompimento com sucesso está diretamente relacionado a disposição que o terceiro molar está para trás da borda anterior do ramo. Se somente metade da coroa do terceiro molar está atrás do ramo, há uma chance de 50\% de irrompimento normal.

Em termos gerais, a função atual dos terceiros molares está diminuída, e irrompem, freqüentemente, de forma tal que não chegam a estabelecer uma correta oclusão, porque, muitas vezes, ficam retidos no interior das maxilas e da mandíbula, ou ainda porque estão ausentes, congenitamente. Os estudos sobre retenção dentária têm revelado que os terceiros molares são os dentes que apresentam maios índice de impacção, observando-se um percentual bem mais ele vado para os inferiores (NANDA ${ }^{57}$ 1959; GRANDINI et al. ${ }^{32}$ 1966).

DACHI; HOWELL ${ }^{14}$, em 1961, examinaram radiografias da dentição de três mil e oitocentos e setenta e quatro pacientes. Observaram que os dentes mais freqüentemente impactados são, em ordem de freqüência: 1) terceiros molares superiores; 2) terceiros molares inferiores; 3) caninos superiores; e 4) pré-molares inferiores, sendo que do total de terceiros molares presentes, 29,9\% estavam impactados no arco superior e $17,5 \%$ no arco inferior. Não foram notadas 
diferenças na incidência de impacção dos terceiros molares em relação ao sexo, nem predisposição quanto a impacção unilateral ou bilateral. Dos terceiros molares superiores impactados, $15 \%$ apresentaram radiolucidez ao redor de suas coroas, sendo que $2,1 \%$ destes, foram diagnosticados cistos dentígeros. No arco inferior $37 \%$ dos terceiros molares impactados apresentaram imagem radiolúcida e 3,8\% destes, também com diagnóstico de cisto dentígero.

VEGO $^{88}$, em 1962, usando fichas de pacientes não tratados da Fundação Bolton, determinou que o perímetro do arco diminui, em média $8 \mathrm{~mm}$, sendo maior nos casos com a presença dos terceiros molares do que nos casos com agenesia de terceiros molares, e isto foi demonstrado ser estatisticamente significante. Assim sendo, pode ser concluído que os terceiros molares contribuem para o apinhamento antero inferior, eles são uma das causas significante para um grande número de casos.

WILLIS $^{90}$, em 1966, considerou a impacção dos terceiros molares, como a mais freqüente das aberrações dentais. Segundo ele, a diferença entre mandíbulas com e sem impacção dos terceiros molares, estariam no desenvolvimento lateral do processo alveolar. Indivíduos com terceiros molares impactados apresentam estreitamento no desenvolvimento alveolar posterior e na região de inserção do músculo bucinador.

$\mathrm{SHAW}^{76}$, em 1968, relatando o caso de uma paciente com terceiros molares inferiores impactados, analisou o movimento realizado por estes dentes, num período de três anos. Mostrou que o grau de inclinação piorou sensivelmente neste 
período. Concluiu que impacções severas de terceiros molares, ao serem detectadas por exames radiográficos, implicam em sua remoção precoce.

Pesquisando a incidência da impacção dentária em três mil setecentos e quarenta e cinco pacientes da raça negra KRAMER ${ }^{41}$, em 1970 observou que $18,2 \%$ das radiografias panorâmicas examinadas, apresentaram uma ou mais impacções. Deste total, $47,44 \%$ estiveram representados pela impacção de terceiros molares inferiores.

Em pesquisas KAPLAN ${ }^{42}$, em 1974, concluiu que, a presença dos terceiros molares não parece produzir um grau maior de apinhamento antero-inferior. A teoria de que os terceiros molares exercem pressão nos dentes mesiais a eles parece não ser comprovada neste estudo. A associação entre o irrompimento dos terceiros molares e o apinhamento dos dentes anteriores, deixa dúvidas, alguns investigadores dizem sim, outros dizem não. Como em toda pesquisa biológica, o tipo do experimento e a interpretação dos dados podem dar aparentemente respostas conflitantes nas mesmas questões.

SCHULHOF $^{75}$, em 1976, analisou a possibilidade de predizer a impacção dos terceiros molares, considerando ser um fenômeno biológico de difícil precisão. Entretanto, conhecendo-se a distância do ramo ascendente até o segundo molar, a predição da impacção poderia ser realizada. Utilizando métodos computadorizados na predição do crescimento, o espaço disponível para os terceiros molares seria avaliado, com margem de erro de 2,8mm. Esses 2,8mm de erro poderiam ser suficiente para colocar o paciente da condição de dentes impactados, para a condição de ter os terceiros molares irrompidos, mas não em oclusão. Porém, 
não mudariam o prognóstico da impacção a boa oclusão, uma vez que o estudo mostrou haver uma diferença de $10 \mathrm{~mm}$, na média da distância entre segundos molares e o ramo, nos indivíduos com terceiros molares impactados e irrompidos.

Em trabalhos, GRABER ${ }^{30}$, em 1976, indicou que, existem muitos fatores envolvidos no irrompimento dos terceiros molares, incluindo entre eles a sua direção. Esta é a razão pela qual não podemos somente discutir a chance de irrompimento em função do espaço disponível. Aqueles que esperam um irrompimento apropriado rotineiramente como conseqüência de extrações de prémolares, ficará desapontado. No mesmo ano Ricketts, verificou que os terceiros molares preocupam os ortodontistas com relação ao tratamento ortodôntico, em qualquer época. Relatou que, na tentativa de conseguir espaço para os incisivos, ou durante o preparo de ancorage m, o movimento para distal dos primeiros molares poderia resultar em diminuição do espaço para os terceiros molares. Também SCHULHOF $^{75}$, no mesmo ano, relatou que para o clínico geral os terceiros molares tem aspectos positivos e negativos. No aspecto positivo, eles podem ser usados para repor dentes perdidos (segundos molares), proporcionar suporte vertical que é crítico para a articulação temporo-mandibular, ou pode ser usado como pilar para pontes fixas. No aspecto negativo eles podem reter alimentos, serem difíceis de higienizar, contribuir para o aparecimento de doenças periodontais, causar dor ao pacientes, e o pior, ocorrer a diferenciação remanescente epitelial para o carcinoma de células escamosas, tem sido reportado devido a terceiros molares impactados. Os negativos facilmente superam os positivos, resultando na extração de terceiros molares em $75 \%$ da população. Em encontros recentes, tem sido discutido a predição de crescimento, os efeitos do espaço disponível na impacção, a enucleação de terceiros molares, isto 
tem aberto novas esperanças de que problemas associados à terceiros molares serão diminuídos no futuro.

RICHARDSON ${ }^{65}$, em 1977, encontrou alta proporção de terceiros molares retidos na Classe II esquelética, com a mandíbula curta e estreita, com o ângulo goníaco mais fechado, principalmente aos 18 anos de idade.

No ano seguinte, MERRIFIELD ${ }^{54}$ considerou muitos ortodontistas culpados em criar discrepâncias posteriores severas. Estas seriam produzidas ao serem feitos ajustes em outras áreas dos arcos médios e anterior. A culpa, também, recairia sobre os que não utilizam a sobra de espaço na região posterior, quando presente, para ajudar a aliviar deficiências de espaços dos arcos médios e anterior.

Em 1978, RICHARDSON ${ }^{66}$ verificou dentes com impacção horizontal ou medio-angular e observou que, freqüentemente, a raiz distal apresentava-se mais comprida e com curva mesial. Ao mesmo tempo, os dentes com impacção vertical ou disto-angular apresentava-se de uma forma geral, com a raiz mesial maior e curvada para distal. Em 1982 estudou 51 pessoas, 22 homens e 29 mulheres, apresentando ambos os terceiros molares e todos com tratamento ortodôntico, somente no arco superior, observou que os casos com impacção dos terceiros molares inferiores possuíam dentes maiores que os casos sem impacção.

Em 1979, RICKETTS ${ }^{73}$ prognostica que se a arcada dentária é movimentada distalmente esperar-se-ia a perda de espaço molar, ao mesmo tempo se criássemos espaço para a mesial e movimentassemos os dentes neste sentido, seria esperado melhor prognóstico. 
Na conferência sobre os terceiros molares no "National Institute of Dental Research", BISHARA; ANDREASEN ${ }^{6}$, em 1983, relataram que, a maioria dos participantes consideram o tratamento ortodôntico uma terapia, que pode requerer movimento em direção distal dos primeiro e segundos molares. Esta movimentação poderia ser tanto por inclinação quanto por translação, podendo resultar em impacção dos terceiros molares.

MOYERS $^{55}$, em 1980, os terceiros molares podem ser considerados como impactados, isto é, os dentes não podem irromper devido ao seu impedimento, mesmo quando iniciaram o desenvolvimento em suas posições normais. A impacção dos terceiros molares é um problema freqüente e sério no homem moderno. Embora diversas medidas possam ser usadas para diferenciar grupos com terceiros molares impactados daqueles sem, um prognóstico cuidadoso da impacção do terceiro molar na idade de 10 a 11 anos não é possível de modo estatisticamente significativo. Alguns clínicos fazem tal prognóstico e os métodos são engenhosos e interessantes, mas nenhum dos procedimentos até agora sugeridos resistiu ao teste crítico, nem é suficientemente preciso para prognósticos corretos em casos individuais.

LINDQUIST; THILANDER ${ }^{48}$, em 1982, extraíram terceiros molares, unilateralmente, em 52 pacientes e encontraram maior estabilidade nas condições de espaço no lado da extração comparado com o lado controle, em 70\% dos casos. 


\subsection{Processos patológicos associados}

O irrompimento incompleto dos terceiros molares é um dos maiores problemas da Odontologia, devido a sua frequiência e implicações clínicas. Embora possam permanecer impactados e assintomáticos por toda a vida, estão comumente associados com processos patológicos, que vão de simples cáries e pericoronarite até cistos ou lesões neoplásicas GOBLIRSCH ${ }^{28}$ 1930, DACHI ${ }^{14}$ 1961, LASKIN ${ }^{44}$ 1969; CHACONAS ${ }^{11}$ 1980. Muitos dentistas consideram os terceiros molares como verdadeiras "doenças dentais", equivocadamente, pois não estão na cavidade bucal tal qual um apêndice sem função. Ironicamente chamado de "dente do juízo" ou siso, o terceiro molar é conhecido como causador de uma variedade de complicações, não necessariamente comprovadas. Assim, seu papel como agente etiológico do apinhamento de incisivos inferiores, pós tratamento ortodôntico, é bastante discutível. A recomendação para a remoção dos terceiros molares como forma de prevenção para futuras patologias, sem especificar sua freqüência, deve ser questionada. Um dos problemas mais freqüentes que estes dentes provocam, ao estarem impactados, é a destruição do segundo molar adjacente. Isto, no entanto, não significa que todos os terceiros molares devam ser extraídos, pois havendo espaço para irromperem e se a angulação do seu longo eixo estiver correta, todo esforço deve ser realizado para preservar estes dentes.

Já, HENRY; MORANT ${ }^{36}$, em 1936, classificaram os sintomas associados com o irrompimento dos terceiros molares em dois grupos; o primeiro demonstrado pela depressão causada, especialmente durante o período de 
irrompimento ativo e no segundo aqueles associados a infecções pronunciadas, até mesmo, por infecções sépticas fatais.

Citando os registros do Bolton Study”, BROADBENT ${ }^{10}$ em 1943, há evidências provando, por conclusão, que a proporção do número de dentes ausentes congenitamente, ou perdidos precocemente, causam profundo efeito nas estruturas de suporte dos dentes e da face, como um todo.

Em trabalho posterior, $\mathrm{GRABER}^{29}$, em 1961, apresentou o problema do terceiro molar como sendo não somente uma experiência dolorosa, como também aqueles que causam distúrbios funcionais, podendo afetar a dentição. Isto pode criar ou agravar problemas na articulação temporo-mandibular.

Continuando a mesma linha de pesquisa, $\mathrm{HOEK}^{38}$ em 1964, observou que mesmo que os terceiros molares irromperem favoravelmente e estabeleçam boa relação com seus antagonistas, seriam de pouco uso ao indivíduo. Apesar do posicionamento favorável, poderiam causar diversos problemas, tais como: dificuldade de higienização, contatos prematuros e, até mesmo, problemas na articulação temporo-mandibular.

LASKIN ${ }^{44}$, em 1969, analisando as indicações e contra indicações para a remoção dos terceiros molares impactados, considerou que estes dentes podem permanecer assintomáticos por toda a vida, mas freqüentemente estão associados a processos patológicos. Estes problemas podem variar de simples cáries dentárias até situações mais sérias como a formação de cistos ou o desenvolvimento de lesões neoplásicas. 
Em 1972, BJÖRK; SKILLER ${ }^{7}$ não encontraram evidência clara que o apinhamento secundário fosse causado pelos terceiros molares.

Parece ser sensato a indicação da extração destes dentes, mediante o estabelecimento de alguns critérios FRIEDMAN ${ }^{24} 1977$ e $\mathrm{NIH}^{58}$ 1980. Alguns tópicos precisam ser abordados, como: 1) a possibilidade de irromperem ou de ficarem impactados quando movimentos distais de primeiros e segundos molares são necessários no decorrer do tratamento; 2) a repercussão da extração de pré-molares ou de outros dentes permanentes, em seu posicionamento; 3) a época em que geralmente o tratamento ortodôntico é terminado, coincidindo com os estágios finais de desenvolvimento da dentição.

Porém, esta teoria não foi aceita por KAPLAN ${ }^{42}$, que em 1982, relacionou os terceiros molares inferiores com o apinhamento secundário após a contenção do tratamento ortodôntico e verificou que estes dentes não influenciaram nas mudanças pós-tratamento em relação ao comprimento do arco, posição do molar inferior e inclinação axial do incisivo inferior.

AZAZ; TAICHER ${ }^{3}$, em 1982, citaram diversos problemas que podem ocorrer com a impacção dos terceiros molares, tais como: pericoronarite, cáries, problemas periodontais, cistos, reabsorções radiculares dos molares adjacentes e dificuldades para o tratamento ortodôntico. 


\subsection{Procedimentos terapêuticos}

HENRY; MORANT ${ }^{36}$, em 1936, fizeram experimentos com a enucleação do germe de terceiros molares antes da calcificação (em média aos 8 anos de idade), e nenhum efeito colateral adverso foi relatado. Segundo os autores, se houvesse método confiável de predição que indicasse a futura impacção de um ou de ambos os terceiros molares, estes dentes poderiam ser extraídos, como medida profilática.

HILLIN $^{37}$, em 1947, recomendou a exodontia dos terceiros molares com impacção antes da formação completa das raízes e antes que as estruturas adjacentes se tornassem mais calcificadas.

LEDYARD JUNIOR ${ }^{46}$, em 1953, observou que os terceiros molares tem sido considerados como culpados quanto à estabilidade final do tratamento ortodôntico e como rotina normal eram indicados a sua remoção, sem qualquer diagnóstico. $\mathrm{O}$ autor sugere que, a decisão para a remoção ou não destes dentes, poderia ser protelada até o final do tratamento ortodôntico, onde seria avaliado o espaço para estes dentes.

Seguindo a mesma linha de estudo, BJÖRK; ELLI ${ }^{8}$, em 1956, recomendaram as extrações dos terceiros molares nos casos onde fossem diagnosticados falta de espaço para eles.

Em 1961, BERGSTRON; JENSEN ${ }^{4}$, observaram 60 indivíduos com a finalidade de determinar o tempo que os terceiros molares causariam apinhamento dentário secundário. Verificaram que estes dentes dão a impressão de 
exercerem alguma influência no desenvolvimento do arco dental, mas não a ponto de as suas extrações serem recomendadas.

$$
\text { LASKIN 44,45, em } 1969 \text { e 1971, recomendou as extrações dos }
$$

terceiros molares logo que se verificasse falta de espaço ou posição anormal de irrompimento. Esta decisão poderia ser aplicada entre as idades de 16 e 17 anos. Contra-indicou a extração destes dentes nos casos onde iriam ser tratados ortodonticamente, com extrações de quatro primeiros pré-molares ou quando estes iriam ser usados como ancoragem. O autor em 1971, considerou a indicação para extração dos terceiros molares um dados importante que deve ser planejado, independentemente do ponto-de-vista, entre ortodontistas e cirurgiões dentistas.

$$
\text { RICKETTS }^{72} \text {, em 1976, chegou a mesma conclusão, porém }
$$
encontrou poucos cirurgiões dispostos a realizar a cirurgia de enucleação. Ele relatou que o procedimento leva menos de cinco minutos para cada dente e que o paciente retorna á escola no mesmo dia, parece ser a enucleação dos terceiros molares totalmente viável e muito menos traumático do que esperar pela impacção.

Para LYTLE ${ }^{49}$, em 1979, a indicação para a remoção precoce de dentes impactados durante o tratamento ortodôntico, é indicada quando o ortodontista determinar que tal remoção facilitará em todo o tratamento do caso.

Considerando a remoção precoce dos terceiros molares, RICKETTS $^{73}$, em 1979, através da sua enucleação, na idades de sete a nove anos, como sendo bastante simples, quando comparada ao grau de dificuldade que a extração destes dentes oferecem, ao estarem impactados na idade adulta. Apresentou trabalhos sugerindo que de 20 a 50\% da população irá perder os terceiros molares. 
Sugeriu também que, de 25 a $30 \%$ da população nunca terá estes dentes em condição normais de uso, mesmo nos casos em que extrações de pré-molares sejam realizadas, como parte do tratamento ortodôntico. O autor recomendou a tomada de radiografias cefalométricas laterais, na idade de seis a oito anos, avaliando a localização da cripta do terceiro molar. Nos casos onde for evidente a falta de espaço, para o total irrompimento dos terceiros molares, será aconselhável a enucleação do folículo imediatamente, ao invés de ser permitida a sua formação e o estabelecimento da impacção destes dentes.

THUROW ${ }^{85}$, em 1982, disse que os terceiros molares poderiam ser importantes na dentição adulta nos casos onde ocorresse a perda de primeiros ou segundos molares. Porém, considerou, em determinados casos, que a remoção de tais dentes contribui para a saúde da dentição, principalmente a de dentes adjacentes.

Já para RICHARDSON ${ }^{68}$, em 1982, a indicação das extrações dos terceiros molares relacionando-os à impacção e não como medida profilática de apinhame nto secundário.

Continuando a mesma linha de pesquisa, AZAZ; TAICHER ${ }^{3}$, em 1982, expuseram que, freqüentemente, pacientes e cirurgiões-dentistas clínicos questionam a necessidade de se removerem os terceiros molares em impacção. Se o paciente não apresentar sintomas, não indicam as extrações. Nos casos de impacção profunda não causariam sintomas clínicos nos estágios patológicos iniciais. 


\subsection{Terceiros molares e extrações de dentes permanentes}

Apresentando indicações de extrações de dentes em procedimentos ontodônticos, TWEED ${ }^{84}$, em 1944, esclarece que todos os dentes deveriam ser mantidos o mais integralmente possível. No entanto, em seus pacientes já tratados constatou surpreso que, o seu sucesso era menor do que $20 \%$ e seus insucessos maiores que $80 \%$. Quanto a Classe II, afirmou que, aqueles tratados com este tipo de má oclusão, apresentaram mandíbulas que estavam ainda subdesenvolvidas embora na maioria dos casos, as relações cuspídeas tivessem sido alteradas com sucesso. Isso foi conseguido deslocando os dentes inferiores mesialmente e os superiores distalmente. Assim, o resultado do tratamento foi a troca de uma má oclusão de Classe II por outra, com uma protrusão maxilar.

STEINER $^{80,81}$, em 1960 e 1962, na confecção do plano de tratamento ortodôntico, de casos com extrações de pré-molares, haveria de ser considerado o valor de 7,5mm, como sendo a largura da coroa destes dentes. Ambos os lados somados perfazeriam um total de $15 \mathrm{~mm}$. Com bons procedimentos durante o tratamento, aproximadamente um terço desse espaço seria perdido pelo movimento para frente dos molares, ou seja, 5mm, assim como, quando das extrações dos segundos pré-molares, a perda média de espaço seria de $10 \mathrm{~mm}$.

CHIPMAN $^{12}$, em 1961, considerou ser pouco recomendável, do ponto de vista clínico, a extração dos segundos molares inferiores na expectativa do irrompimento dos terceiros molares. Os terceiros molares inferiores estariam, normalmente, numa inclinação axial desfavorável e por esta razão não irromperiam em boa oclusão, ficando distante da área de contato proximal. 
FANNING $^{20}$, em 1962, pesquisou jovens de ambos os sexos com dentições completas e mutiladas, questionando as extrações de outros dentes permanentes sobre os terceiros molares. Foram analisados três mil quatrocentos e vinte e três estudantes, sendo dois mil trezentos e setenta do sexo masculino e mil e cinqüenta e três do sexo feminino, com idade variando dos treze aos vinte e dois anos. Radiografias foram tiradas para observação dos terceiros molares e levando o histórico da extração de outros dentes permanentes irrompidos ou impactados. Desta forma, o grupo foi dividido em duas categorias, sendo um composto de indivíduos que haviam extraído um ou mais dentes permanentes e outro com a dentição completa. Foi observado que nas dentições não mutiladas os terceiros molares emergiram, em média, aos dezenove anos e oito meses e vinte anos e quatro meses de idade, para homens e mulheres respectivamente. Quando um ou mais dentes permanentes haviam sido extraídos, notava-se uma aceleração no irrompimento dos terceiros molares sendo, em média, 1,7 anos mais cedo nos homens e 1,5 anos nas mulheres. $\mathrm{O}$ autor concluiu que o irrompimento dos terceiros molares é influenciada pela extração de outros dentes permanentes.

PERLOW ${ }^{61}$, em 1964, salientou que a responsabilidade do ortodontista que extrai pré-molares não termina, até a definição da posição dos terceiros molares. O profissional deveria fazer tudo que estivesse ao seu alcance, do ponto de vista estético e moral, para obter uma boa oclusão funcionalmente estável e com vinte e oito dentes. Considerou ainda que, quando um tratamento adequado é realizado, os terceiros molares movem-se para a frente e naturalmente para baixo, devendo ser observados alguns fatores, como: 1) seleção da extração de segundos pré-molares, sempre que possível, ao invés de primeiros pré-molares, o que 
melhoraria a situação consideravelmente; 2) eliminação de "tip back bendes" severos, que impediriam o irrompimento dos terceiros molares; 3) educar o paciente e seus responsáveis quanto a importância dos terceiros molares. Rever o paciente aos 17 anos de idade através de exames clínico e radiográfico, avaliar a posição destes dentes. Muitas vezes, uma simples mola de separação, associada com pequena cirurgia no tecido, é suficiente para colocar os terceiros molares em posição correta.

$\mathrm{McCOY}^{31}$, em 1965, analisando casos tratados com extrações de pré-molares, questionou a idéia de que fechando-se os espaços das extrações, haveria um movimento mesial dos molares, o que preveniria a impacção dos terceiros molares inferiores. $\mathrm{O}$ autor observou que na maioria dos casos tratados com extrações verificava-se a presença de terceiros molares inferiores impactados.

Analisando as implicações do terceiro molar no tratamento ortodôntico, WEINSTEIN ${ }^{89}$, em 1971, questionou o impedimento que os dentes representam em movimentos, no sentido posterior, com os primeiros e segundos molares. Salientou que o movimento dentário depende da reabsorção óssea e terceiros molares não irrompidos podem causar uma resistência adicional ao movimento do segundo molar, ou impactarem nestas condições. No entanto, quando pré-molares são extraídos, como parte da terapia ortodôntica, haverá um posicionamento mais anterior dos molares. Desta maneira, a decisão da extração dos terceiros molares, que a princípio parecem destinados a impacção, deve ser adiada.

FRIEDMAN $^{24}$, em 1977, considerou que as três maiores causas para perdas de dentes, em indivíduos com menos de trinta e cinco anos, seriam: 1) cárie dental; 2) doença periodontal; 3) o dentista. Na opinião do autor, muitos 
profissionais de Odontologia encaram os terceiros molares como doenças dentais e recomendam sua remoção para prevenção de futuras patologias sem, no entanto, especificar a frequiência destas patologias. Considera ainda, que muitos ortodontistas acusam os terceiros molares como causadores do colapso de seus tratamentos e, ao discordar da idéia, acredita serem os tratamentos com expanção do arco, os maiores responsáveis na recidiva de apinhamentos. Por outro lado, em tratamentos ortodônticos que requeiram movimentos distais de primeiros e segundos molares, será recomendável a remoção dos terceiros molares. Analisando a hipótese de se realizarem tratamentos ortodônticos com a extração de segundos molares permanentes, LIDDLE $^{47}$, em 1977, considerou ser uma opção bastante válida, nos casos em que haja o agravamento do apinhamento anterior em pacientes jovens, onde os terceiros molares ainda não irromperam. A extração de pré-molares será também, em muitos casos uma forma de tratar o efeito e não a causa da má oclusão.

FERNANDES $^{21}$, em 1978, investigou o movimento mesial dos primeiros molares inferiores, em casos tratados ortodonticamente, com extrações de primeiros pré-molares. Pesquisou radiografias cefalométricas, antes e após o tratamento de trinta pacientes, que haviam sido submetidos a correção ortodôntica, sendo todos de Classe I, biprotrusão, com extrações de primeiros pré-molares. Os resultados obtidos indicaram uma perda de um terço do espaço da extração, por migração mesial dos molares, durante o processo de fechamento de espaço.

\section{Promovida pelo "NATIONAL INSTITUTE OF HEALTH",58 em} 1980, aproximadamente duzentos e cinqüenta dentistas, representando todas as disciplinas inerentes à profissão, realizaram um encontro para avaliar quando e quais 
condições a extração dos terceiros molares seria necessária. Consideraram que a terapia ortodôntica em ambos os arcos, superior e inferior, podem requerer o movimento de primeiro e segundos molares no sentido distal, que poderá causar a impacção dos terceiros molares. Para se evitar esta impacção e facilitar o movimento, seria indicado, em alguns casos, a extração de terceiros molares e a necessidade de novas pesquisas, principalmente quanto a relação entre os terceiros molares e o apinhamento, crescimento, desenvolvimento da tuberosidade e área retro-molar, assim como, um bom método para se predizer o irrompimento dos terceiros molares.

QUINN $^{63}$, em 1985, reviu casos tratados com extrações de segundos molares, por período de tempo superior a vinte anos. Observou que este tipo de tratamento pode ser mais recomendável, que aqueles com extrações de prémolares, em muitos casos. Os terceiros molares deveriam ser considerados elementos bastante viáveis no planejamento ortodôntico, uma vez, que em $75 \%$ dos casos onde os segundos molares foram extraídos, eles se posicionaram corretamente em relação aos primeiros molares.

Em vista do que foi estudado em relação aos terceiros molares superiores, especula-se que esses casos tratados com extrações de pré-molares superiores, teriam uma maior probabilidade de terem os terceiros molares irrompidos e em função do que os casos tratados sem extrações de pré-molares superiores. Portanto, com a intenção de se investigar essa especulação decidiu-se comparar a presença e a angulação dos terceiros molares superiores em casos tratados sem e com extrações dos pré-molares superiores. 
Proposição 


\section{PROPOSIÇÃO}

O objetivo deste trabalho foi testar a seguinte hipótese nula: o número de terceiros molares superiores irrompidos e em função, assim como as angulações mesiodistais dos terceiros superiores nesses dois grupos, em casos de Classe II tratados sem extração é semelhante aquele em casos de Classe II tratados com extrações dos pré-molares superiores. Para tanto, serão comparados os números de terceiros molares superiores irrompidos em função, e as angulações mesio-distais dos terceiros molares superiores, entre dois grupos de pacientes com má oclusão de Classe II, tratados sem e com extrações de dois pré-molares superiores. 
Material e Método 


\section{MATERIAL E MÉTODO}

\subsection{Material}

Procedeu-se à seleção da amostra, de caráter retrospectivo, a partir do arquivo da Disciplina de Ortodontia da Faculdade de Odontologia de Bauru Universidade de São Paulo - FOB - USP. A partir de uma amostra inicial de 900 documentações de pacientes tratados com ortodontia corretiva fixa, foram selecionados 55 documentações, divididos em 28 documentações de pacientes para o grupo 1, (tratados sem extrações), com idade média do último controle 19,03 anos (mínima de 14,08 anos e máxima de 23,92 anos) e 27 documentações de pacientes para o grupo 2, (tratados com extrações de pré- molares superiores), com idade média do último controle de 19,94 anos (mínima de 14,75 anos e máxima de 25,67 anos). Os critérios básicos utilizados para a seleção da amostra, foram a presença de relação molar de no mínimo $1 \frac{1}{2}$ Classe II de ambos os lados, a presença de todos os dentes permanentes, podendo estar ausente os $3^{0}$ molares inferiores, ausências de anadontias ou dentes supranumerários e a presença dos terceiros molares superiores na radiografia panorâmica inicial de ambos os lados. Pares de modelos de início do tratamento e do último controle pós-tratamento e 55 radiografias iniciais e do último controle dos pacientes, com os terceiros molares superiores presentes bilateralmente. Para a realização do traçado foi utilizado papel Ultraphan tamanho $14 \times 25 \mathrm{~cm}$, para a mensuração dos ângulos um transferidor Polibras, uma lapiseira 0,5mm, um negatoscópio, blindagem de papel cartão e para as anotações dos ângulos e dados dos pacientes foram usadas fichas próprias. 


\section{2 - Método}

\subsubsection{Avaliação da presença dos terceiros molares superiores irrompidos em função}

Para essa avaliação foram utilizados os modelos dos pacientes selecionados, obtidos no arquivo da Disciplina de Ortodontia da Faculdade de Odontologia da Bauru. Foram utilizados pares de modelos do início do tratamento e do último controle pós-tratamento. Para o grupo 1, tempo médio de controle com os terceiros molares superiores de 4,83 anos (mínimo de 1ano e máximo de 9,17 anos) e para o grupo 2, tempo médio de controle com terceiros molares superiores de 4,89 anos (mínimo de 1 ano e máximo de 10,25 anos). Nesses modelos foram computados, em fichas próprias, a quantidade de terceiros molares superiores que estivessem irrompidos e em oclusão, para cada grupo. Considerou-se que os dentes estavam em oclusão quando apresentassem contato com os dentes inferiores.

\subsubsection{Avaliação das angulações mesiodistais dos terceiros molares superiores}

\subsubsection{Radiografias panorâmicas}

Foram utilizadas 55 radiografias iniciais e do último controle dos pacientes, com os terceiros molares superiores presentes bilateralmente. 


\subsection{Elaboração dos traçados anatômicos}

Adaptou-se sobre cada radiografia uma folha de papel "Ultraphan" de tamanho $14 \times 30 \mathrm{~cm}$, e em seguida, com um lapiseira de $0,5 \mathrm{~mm}$, traçoutse sobre o negatoscópio as estruturas anatômicas. Estes traçados foram efetuados em sala escurecida com o auxílio da blindagem de papel cartão, pois a visualização dos reparos anatômicos torna-se mais evidente.

\subsection{Estruturas dentoesqueléticas}

O traçado constou dos perfis representativos dos seguintes reparos anatômicos, TAVANO, et $\mathrm{al}^{83}$ :

- contorno inferior das cavidades orbitárias,

- contorno das tuberosidades maxilares,

- contorno do palato ósseo,

- espinha nasal anterior, e

- contorno externo dos terceiros molares superiores. 


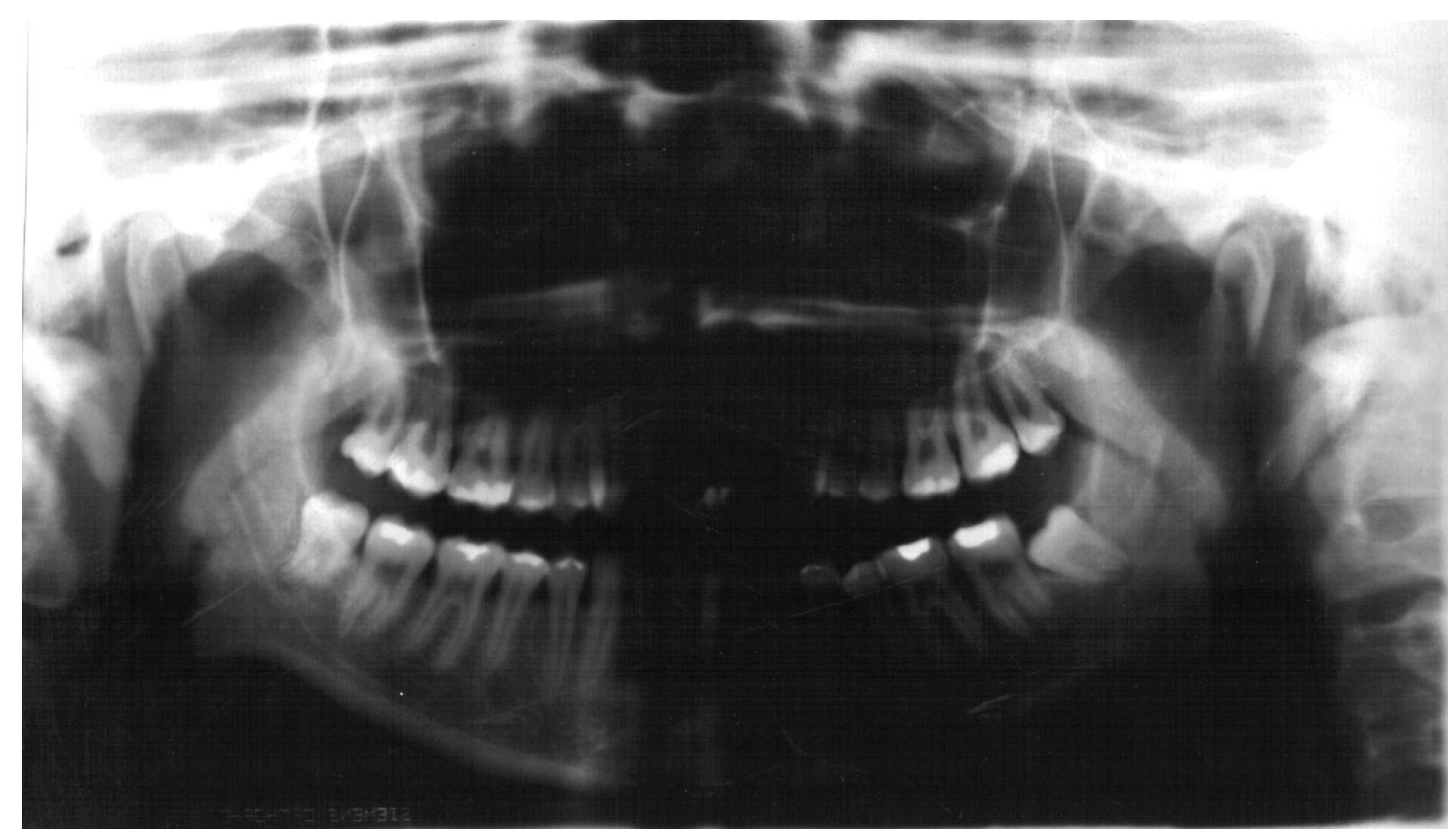

Figura 1 - Reparos Anatômicos.

\subsection{Demarcação dos pontos e traçado das linhas de referência}

Foram empregados pontos e linhas de acordo com TAVANO, et $\mathrm{al}^{83}$ :

\subsection{Pontos}

- orbital direito - ord - e esquerdo - ore: pontos mais inferiores das cavidades orbitárias.

- tuberosidades direita - tbd - e esquerda - tbe: pontos formados pelas perpendiculares vertical e horizontal das tuberosidades da maxila. 


\subsection{Linhas}

As linhas traçadas a partir da identificação dos pontos foram:

- linha interorbital - IO : linha passando por ord e ore,

- linha intertuberosidade - IT : linha passando por tbd e tbe.

- longo eixo dos terceiros molares superiores: foram traçados os longos eixos dos terceiros molares superiores direito e esquerdo irrompidos ou não, passando pela trifurcação das raízes dos terceiros molares superiores e no canal radicular mais central e meio da coroa clínica medido a partir do centro da face cervical e oclusal.

\subsection{Mensuração dos ângulos}

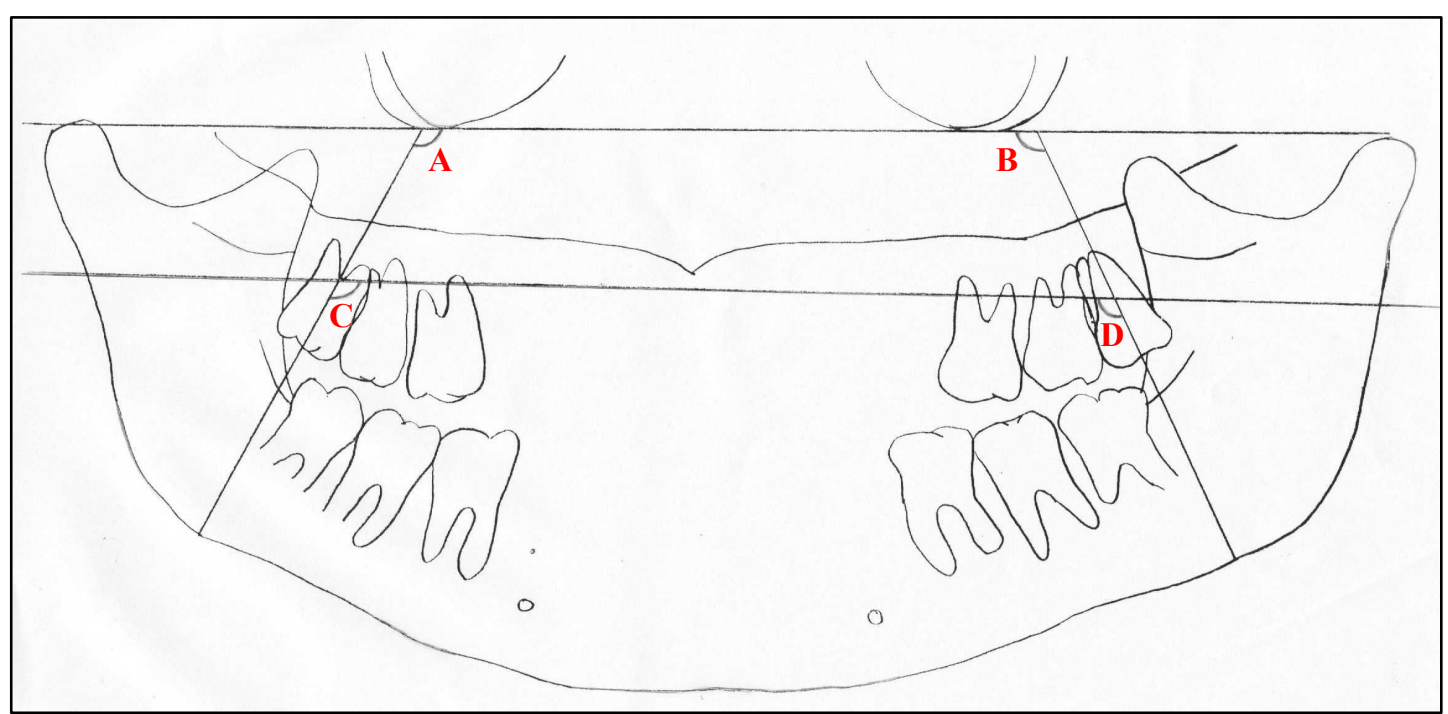

Figura 2 - Ângulos formados pelos longos eixos dos dentes superiores e a linha interorbital e longos eixos dos dentes superiores e a linha intertuberosidade. 
Após a demarcação dos pontos e linhas, passou-se a mensuração manual dos ângulos, formado pelo longos eixos dos terceiros molares superiores e as linhas de referência utilizadas para o arco superior. Fig. 1

- ângulos formados pelo longos eixos dos terceiros molares superiores direito e esquerdo e a linha interorbital. Fig. A e B

- ângulos formados pelos longos eixos dos terceiros molares superiores direito e esquerdo e a linha intertuberosidades. Fig. C e D

Foram utilizados os ângulos formados pelos terceiros molares superiores e a linha intertuberosidades, porque nem todas as radiografias apresentavam as órbitas para permitir a mensuração por essa estrutura. Sendo que, no total da amostra (55 documentações), 7 radiografias panorâmicas as órbitas não estavam presente, portanto não podendo ser medidas.

\subsubsection{Análise estatística}

\subsubsection{Erro do método}

Para a avaliação do erro intra-examinador, foram traçados e medidos novamente todos os ângulos das radiografias panorâmicas de quinze pacientes de ambos os grupos, selecionados aleatoriamente, com 4 medidas para cada uma, somando-se um total de 60 medidas. A obtenção do erro sistemático procedeu- 
se pela aplicação do teste t pareado, de acordo com HOUSTON ${ }^{43}$ (1983). Para avaliação do erro casual, empregou-se o teste de Dahlberg, o qual demonstra a variação média entre a primeira e a segunda medição, com a seguinte fórmula: $E=\sqrt{ } \sum d^{2} / 2 n$

\subsubsection{Comparação entre os grupos}

\subsection{Teste do Qui-quadrado}

Para a comparação da quantidade de terceiros molares irrompidos e em função entre os grupos foi utilizado o teste do Qui-quadrado, com o programa Statistica. Os resultados foram considerados estatisticamente significantes para $\mathrm{p}<$ 0,05 .

\subsection{Teste t para variáveis independentes}

Para a comparação das angulações mesiodistais dos terceiros molares entre os grupos foi utilizado o teste $\mathrm{t}$ para variáveis independentes. Os resultados do teste t foram considerados estatisticamente significantes para $\mathrm{p}<0,05$. 
Resultados 


\section{RESULTADOS}

Os resultados estão apresentados em forma de tabelas. Na Tabela 1 estão dispostos os valores dos erros casuais e sistemáticos, da avaliação intraexaminador.

Tabela 1 - Apresentação dos erros casuais (Dahlberg) ${ }^{15}$ e dos resultados do teste $\mathrm{t}$ para amostras dependentes, do teste intra-examinador, os resultados apresentados em ângulos.

\begin{tabular}{lrrrrrr}
\hline \multicolumn{1}{c}{ Variáveis } & \multicolumn{2}{c}{$\mathbf{1}^{\mathbf{a}}$ Medição } & \multicolumn{5}{c}{$\mathbf{2}^{\text {a }}$ Medição } \\
& Média & D.P. & Média & D.P. & Dahlberg & P \\
\hline \hline Orb.D & 116,73 & 8,43 & 116,53 & 7,21 & 3,6101 & 0,885472 \\
Orb.E & 114,53 & 11,92 & 115,33 & 11,21 & 3,8122 & 0,583384 \\
Med.Orb.D.E. & 115,36 & 8,58 & 115,93 & 7,80 & 2,8121 & 0,598605 \\
Mx.D. & 116,80 & 7,86 & 116,06 & 7,24 & 3,7727 & 0,611728 \\
Mx.E. & 114,60 & 11,19 & 116,00 & 10,52 & 4,1352 & 0,371863 \\
Med.Mx.D.E. & 115,70 & 8,40 & 116,03 & 7,69 & 3,0577 & 0,776608 \\
Orb.Mx.D & 124,46 & 30,55 & 116,30 & 7,15 & 4,0280 & 0,290113 \\
Orb.Mx.E & 114,56 & 11,50 & 115,66 & 10,82 & 3,9253 & 0,461938 \\
Méd.Orb.Mx. & 115,50 & 8,47 & 115,94 & 7,73 & 2,9079 & 0,693292 \\
\hline \hline
\end{tabular}


Tabela 2 - Teste do Qui-quadrado

Foram utilizados modelos do último controle.

\begin{tabular}{ccccc}
\hline \hline Variáveis & Irrompidos & $\begin{array}{c}\text { Não } \\
\text { Irrompidos }\end{array}$ & $\begin{array}{c}\text { Total } \\
\text { Dentes }\end{array}$ & $\begin{array}{c}\text { Total } \\
\text { Pacientes }\end{array}$ \\
\hline \hline $\begin{array}{c}\text { Grupo 1 } \\
\text { Sem Extrações } \\
\text { Grupo 2 }\end{array}$ & 12 & 44 & 56 & 28 \\
Com extrações & 24 & 30 & 54 & 27 \\
\hline $\mathrm{X}^{2}=6,62$ & & & & \\
$\mathrm{P}=0,01$ & & &
\end{tabular}

Tabela 3 - Resultado do teste t independente do último controle, entre os grupos 1 e 2.

\begin{tabular}{lccccc}
\hline \multicolumn{1}{c}{ Variáveis } & \multicolumn{2}{c}{ Grupo 1 } & \multicolumn{2}{c}{ Grupo 2 } \\
& Média & D.P. & Média & D.P. & P \\
\hline \hline Orb.D & 119,13 & 13,50 & 111,32 & 12,64 & 0,044133 \\
Orb.E & 118,95 & 13,17 & 111,28 & 11,25 & 0,034754 \\
Med.Orb.D.E. & 119,04 & 11,07 & 111,30 & 10,22 & 0,015288 \\
Mx.D. & 119,00 & 14,97 & 109,59 & 15,75 & 0,027268 \\
Mx.E & 121,00 & 12,58 & 111,07 & 12,17 & 0,004459 \\
Med.Mx.D.E. & 120,00 & 11,38 & 110,33 & 12,57 & 0,004209 \\
Orb.Mx.D. & 119,15 & 13,85 & 111,34 & 12,35 & 0,044579 \\
\hline Orb.Mx.E & 118,82 & 12,71 & 111,24 & 11,19 & 0,033007 \\
\hline Med.Orb.Mx. & 118,98 & 11,03 & 111,29 & 10,21 & 0,015666 \\
\hline \hline p<0,05 & & & & & \\
\hline
\end{tabular}




\section{Lista de abreviaturas:}

Orb.D - ângulo formado entre o $3^{\circ}$ molar superior direito e a linha inter-orbital.

Orb.E - ângulo formado entre o $3^{\circ}$ molar superior esquerdo e a linha inter-orbital.

Med.Orb.D.E. - média dos ângulos formados entre os $3^{0}$ molares superiores direito e esquerdo e a linha inter-orbital.

Mx.D - ângulo formado entre o $3^{\circ}$ molar superior direito e a linha intertuberosidades.

Mx.E - ângulo formado entre o $3^{\circ}$ molar superior esquerdo e a linha intertuberosidades.

Med.Mx.D.E. - média dos ângulos formado entre os $3^{\circ}$ molares superiores direito e esquerdo e a linha inter-tuberosidades.

Orb.Mx.D - média entre os ângulos formados entre os $3^{\circ}$ molares superiores direito e as linhas inter-orbitais e inter-tuberosidades.

Orb.Mx.E - média dos ângulos formado entre os $3^{\circ}$ molares superiores esquerdo e as linhas inter-orbitais e inter-tuberosidades.

Med.Orb.Mx. - média dos ângulos formado entre os $3^{\circ}$ molares superiores direito e esquerdo e as linhas inter-orbitais e inter-tuberosidades. 


\section{DISCUSSÃO}

Com o propósito de facilitar o entendimento e interpretação dos resultados obtidos com esta pesquisa, serão discutidos seqüencialmente, a amostra utilizada, a metodologia empregada, a precisão da metodologia e os resultados obtidos.

\subsection{Da amostra utilizada}

Para a obtenção da amostra foram selecionados os modelos iniciais e último controle, também foram utilizadas as fichas clínicas e as radiografias panorâmicas iniciais e último controle com os terceiros molares superiores presente em ambos os lados. Foram selecionados documentações de pacientes que apresentassem inicialmente relação molar de pelo menos 1/2 Classe II de ambos os lados e tratados com a mecânica ortodôntica corretiva fixa superior e inferior, sem e com extrações de pré-molares superiores. Não houve preocupação em se diferenciar se foram extraídos primeiros ou segundos pré-molares nos casos a serem avaliados. Foram selecionados somente casos com relação molar de pelo menos $1 / 2$ Classe II. Os demais foram eliminados da amostra porque discrepâncias ântero-posteriores muito pequenas diluem demais as características de casos de Classe II. Além do mais, como o objetivo era a avaliação do espaço para o irrompimento dos terceiros molares superiores e suas inclinações axiais mesiodistais dos dois lados, era condição imprescindível que a relação molar fosse de Classe II simétrica. 
Outro critério utilizado foi a presença de todos os dentes permanentes, podendo estar ausente os terceiros molares inferiores. A ausência de algum dente pode, em determinadas situações, favorecer ou complicar a correção dessa má oclusão e isso poderia interferir nos resultados também.

A amostra inicial constituiu-se de 83 documentações de pacientes obtida de um total de 900 documentações. Foram divididos em dois grupos experimentais, o grupo 1 com 44 pacientes e o grupo 2 com 39 pacientes. A seleção mais específica dos casos ocasionou uma diminuição do número de componentes da amostra. No grupo 1, 6,8\% dos pacientes apresentavam $1 / 4$ de Classe II, 6,8\% dos pacientes não foi possível encontrar a pasta no arquivo, 6,8\% dos pacientes apresentavam agenesia unilateral de terceiros molares superiores e 15,9\% dos pacientes não tinham um controle radiográfico pós-término de tratamento. Já no grupo 2, 12,8\% dos pacientes apresentavam $1 / 4$ de Classe II, 5,1\% dos pacientes não foi possível encontrar as pastas no arquivo e $12,8 \%$ dos pacientes não tinham controle radiográfico pós-término de tratamento.

Portanto, satisfazendo esses critérios, foram encontrados um total de 55 documentações de pacientes, sendo 28 pacientes do grupo 1 e 27 pacientes do grupo 2, dentre um total de 900 documentações de pacientes já tratados nos cursos de pós-graduação e especialização da Disciplina de Ortodontia da Faculdade de Odontologia de Bauru. Pode parecer pouco dentro da proporção de pacientes com má oclusão de Classe II que geralmente constituem o grande universo de uma clínica ortodôntica. Entretanto, deve-se lembrar que os critérios estabelecidos eliminaram uma grande parte dos pacientes potenciais. Adicionalmente, convém mencionar que 
apesar dos esforços para o arquivamento de toda a documentação dos pacientes tratados na disciplina, havia alguns casos que não apresentavam todas as radiografias panorâmicas, alguns modelos e fichas clínicas não foram encontrados não podendo ser assim incluídos nessa avaliação.

Entretanto o número de pacientes utilizados pode ser considerado suficiente para conferir confiabilidade aos resultados, levando em consideração que outros trabalhos semelhantes utilizam amostras de tamanho compatível ao presente estudo. Reforçando esse argumento RICHARDSON ${ }^{70}$ (1987) e $\operatorname{DIERKES~}^{17}$ (1975), relataram que, infelizmente, grupos experimentais compostos por um grande número de pacientes são difíceis de se encontrar.

\subsection{Metodologia}

\subsubsection{Da inclinação axial mesiodistal}

Desde os primeiros passos dessa pesquisa houve a preocupação de que a importância das inclinações axiais mesiodistais deveriam ser realçadas a fim de uma melhor compreensão de nossos objetivos e suas diversas implicações. WHEELER $^{87}$ em 1965, argumentou que é comum a ocorrência de variações, segundo o autor, nos arcos dentários, ocorre a propensão a inclinação dos longos eixos dos dentes, uma vez que não se encontram implantados verticalmente no osso alveolar. Normalmente, os dentes encontram-se com as coroas inclinadas para mesial em graus variáveis. 
No arco superior todos os dentes possuem seus longos eixos desviados para distal, especialmente os molares DEWEL ${ }^{16}$ (1949), PICOSSE $^{62}$ (1971) e BERKOWITZ et al. ${ }^{5}$ (1977), fizeram observações similares, constatando a tendência ao paralelismo radicular e a inclinação dos ápices para distal. Existe também um componente de forças no sentido mesial, espalhado na inclinação apresentada pelos dentes, que por sua vez, é causado pelo padrão funcional do mecanismo da mastigação. Neste trabalho encontramos um melhor posicionamento para o irrompimento dos terceiros molares superiores, mais verticalizados, nos casos tratados com extrações de pré-molares superiores, vindo comprovar o componente de força das coroas no sentido mesial e a inclinação dos ápices das raízes para distal, segundo PICOSSE ${ }^{62}(1971)$.

\subsubsection{Do método radiográfico}

O desenvolvimento das radiografias panorâmica como meio auxiliar de diagnóstico em odontologia iniciourse com PAATERO ${ }^{59}$, que em 1948 desenvolveu o primeiro aparelho destinado a este fim, a partir de conceitos e princípios de outros pesquisadores, culminando em 1961 com o aparecimento do Ortopantógrafo. Desde então, vem sendo utilizada estas radiografias e seu aperfeiçoamento é constante, facilitando o manuseio do aparelho e melhorando a qualidade das imagens obtidas, tornando-se hoje, obrigatória em quase todos os ramos da odontologia.

Como em qualquer tipo de radiografia, as imagens de um aparelho panorâmico têm uma dimensão sempre maior que a real, devido à própria geometria 
da formação da mesma, não sendo possível o estabelecimento de um único fator de correção para toda a imagem, visto que a relação objeto, filme e fonte de radiação não se mantém constante durante toda a exposição. Estas informações revelam a precariedade das medições lineares, sendo que, no sentido horizontal, além dos fatores distância e o alinhamento do objeto, filme e fonte de raios X, acrescenta-se o agravante da movimentação do tubo, que as predispõem a uma maior distorção, BLACKMAN $^{9}$ (1956) e URSI $^{86}$ (1989). Apesar disto, alguns autores GILBERT ${ }^{27}$ (1962), MITCHELL ${ }^{52}$ (1963) e ISHIKAWA et al. ${ }^{40}$ (1968), verificaram uma boa confiabilidade deste instrumento nas avaliações lineares em estudos longitudinais.

LUND; MANSON-HING ${ }^{50}$, em 1975 concluíram em estudos, que todos os aparelhos pesquisados, foram capaz de radiografar as diversas formas e tamanhos dos arcos dentários, desde que o paciente estivesse bem posicionado. Como todos os pacientes da amostra apresentavam oclusão de Classe II, esta variação no padrão de imagem foi pequena. O que não aconteceria se, por exemplo, a amostra fosse constituída de pacientes com discrepância etárias muito grande ou apresentassem más oclusões com volubilidade extremas de forma e tamanho de arcos dentários. As imagens obtidas dos diversos pacientes apresentaram pequenas variações no seu padrão quanto a curvatura projetada de suas bases ósseas e dos elementos dentários.

TAVANO et al. ${ }^{83}$, em 1989, relatam que as avaliações angulares são menos críticas, apesar da possibilidade de pequenas discrepâncias entre os resultados, que podem ser atribuídas, no funcionamento dos diversos tipos de aparelhos e nas próprias medições. Clinicamente estas diferenças são administradas, 
tendo poucas variações entre uma medida e outra. Foi encontrada uma certa dificuldade nas medições dos ângulos formado nas tuberosidades, pois neste local a sobreposição de estruturas anatômicas é muito grande, entretanto nessa pesquisa o ângulo formado pela órbita e o longo eixo dos terceiros molares superiores, vem confirmar as medições feitas a partir das tuberosidades. No presente trabalho a mensuração dos ângulos foi realizado manualmente, com o auxílio de um transferidor.

\subsection{Precisão da metodologia}

Foram realizadas 4 medidas para cada radiografia panorâmica de pacientes selecionados na amostra. Como a amostra total conta com 55 pacientes, sendo uma panorâmica para cada paciente, ao final foram então realizadas um total de 220 medidas.

Para avaliar os erros da metodologia, HOUSTON ${ }^{39}$ recomenda, idealmente, que as medições sejam realizadas duas vezes. Entretanto, se isto não for possível, aconselha-se que as radiografias sejam selecionadas ao acaso, da amostra total. Neste estudo foram realizados novamente os traçados e as medições de quinze radiografias panorâmicas, escolhidas ao acaso, número este julgado suficiente devido à quantidade de variáveis utilizadas e com base em estudos similares que utilizaram quantidades semelhantes.

A maior fonte de erros casuais, segundo HOUSTON ${ }^{39}$, acontece pela dificuldade de identificação de um ponto. De uma forma geral, os erros casuais 
nesse trabalho foram bastante reduzidos, o que é considerado bastante satisfatório, ao se comparar com a literatura. Adicionalmente, não se encontrou erros sistemáticos entre a primeira e segunda medições (Tabela 1).

\subsection{Resultados}

\subsubsection{Compatibilidade dos grupos}

Mesmo selecionando os pacientes de ambos os grupos de acordo com os critérios mencionados, há possibilidade de os mesmos apresentarem outras características que possam interferir na qualidade entre os grupos da amostra.

O número de pacientes de cada grupo foi bastante semelhante, sendo 28 para o grupo 1, e 27 para o grupo 2. As idades médias do último controle com os terceiros molares presentes foi de 19,03 para o grupo 1 e 19,94 para o grupo 2, portanto, também bastante semelhantes. Uma proporção diferente em relação à idade média entre os dois grupos poderia interferir na época de irrompimento dos terceiros molares, na inclinação axial mesiodistal dos terceiros molares e na sua formação radicular, não podendo desta forma ser possível uma comparação precisa entre os dois grupos. Isto demonstra um alto grau de compatibilidade entre os dois grupos estudados e isenção da interferência de características díspares nos resultados. 


\subsubsection{Resultados em modelos}

Analisando os resultados obtidos, verificou-se que houve uma diferença estatisticamente significante no número de dentes irrompidos e em função, entre o grupo tratado sem extrações (grupo 1) e o grupo tratado com extrações de dois pré-molares superiores (grupo 2), como mostrado na Tabela 2. Esta diferença parece ser o ganho de espaço no segmento posterior, quando o tratamento é realizado com a terapêutica de extrações de dois pré-molares superiores. Isto demonstra que as extrações não possibilitam apenas a correção da má oclusão da Classe II, como também, proporciona uma mesialização do segmento posterior com ganho de espaço para o irrompimento dos terceiros molares superiores. PERLOW ${ }^{61}$ em 1964, salientou que o profissional deveria fazer tudo que estivesse ao seu alcance, para obter uma boa oclusão funcionalmente estável e com vinte e oito dentes. DIERKES ${ }^{17}$ (1975), em estudo mostrou que a remoção de primeiro ou de segundos pré-molares ajuda no surgimento de espaço para o irrompimento dos terceiros molares, quando comparado a grupos sem extrações.

\subsubsection{Resultados radiográficos}

Analisando as medidas angulares das inclinações axiais mesiodistais dos terceiros molares superiores na Tabela 3, verificou-se que no grupo 2, com extrações de pré-molares superiores, os terceiros molares superiores se apresentaram mais verticalizados, com um melhor posicionamento. Como conseqüência, essas variáveis irão invariavelmente refletir também no melhor posicionamento para o irrompimento dos terceiros molares superiores. Esta 
constatação é reforçada por SICHER; DUBRUL ${ }^{78}$ (1970), salientando que as distintas posições dos dentes nos osso alveolar são coincidentes com a direção das forças mastigatórias. Nota-se , uma escassez de trabalhos referentes especificamente à avaliação quantitativa das inclinações axiais dentárias em radiografias panorâmicas, quanto muito, apenas a recomendação para a sua realização, sem que exista um padrão normal para servir como referência, o que eliminaria possíveis variações inter indivíduos, sempre presentes em observações subjetivas. Um trabalho que embora não tivesse este objetivo, mas que se aproximou disto, é o de MLYNARSKA - ZDUANIAK ${ }^{53}$ (1983), que estabeleceu média e desvios padrão para as inclinações axiais dos longos eixos dos dentes permanentes, irrompidos ou não. Em vista disto, nos convencemos da necessidade do estabelecimento deste padrão, que pudesse ser empregado na prática ortodôntica, fornecendo subsídios ao profissional na obtenção de resultados melhores e mais reproduzíveis.

\subsubsection{Implicações clínicas}

Isto confirma, portanto, as especulações dessa forma de tratamento, que requer menor colaboração dos pacientes na utilização de dispositivos extra bucais para a distalização de dentes, de que haverá maior espaço para o irrompimento e função dos terceiros molares superiores, devido ao ganho de espaço no segmento postero-superior, LEDYARD JÚNIOR ${ }^{46}$ (1953). Como consequiência, o irrompimento dos terceiros molares em melhores condições oclusais, diminui-se, desta forma extrações futuras destes dentes. 
PERLOW $^{61}$ (1964), verificou que os terceiros molares movem-se para a frente e verticalizam-se, naturalmente por si só, em pacientes que necessitam de extrações de pré-molares. Ele constatou que, a posição dos terceiros molares impactados melhorou em cerca de $95 \%$ dos casos em que os pré-molares foram removidos.

Em 1976, ANDREWS ${ }^{2}$ salientou que a correta inclinação mesiodistal das coroas, é necessário para a obtenção de pontos de contato satisfatórios, posicionando os dentes posteriores adequadamente, com contatos proximais cerrados, contribuindo desta forma para uma maior estabilidade póstratamento.

\subsubsection{Sugestões para trabalhos futuros}

Comparar e medir o espaço presente para o irrompimento de terceiros molares superiores, entre dois grupos, tratado com e sem extrações de prémolares superiores.

Avaliação da presença clínica e angulação dos terceiros molares superiores em idade mais avançada. 
Conclusões 


\section{CONCLUSÕES}

A hipótese nula foi rejeitada porque:

A quantidade de terceiros molares superiores irrompidos e em função foi estatisticamente maior nos casos tratados com extrações dos pré-molares superiores em relação aos casos tratados sem extrações e as angulações mesiodistais foram estatisticamente menores e parece ser mais favoráveis para o seu irrompimento. 
Referências Bübliográficas 


\section{REFERÊNCIAS BIBLIOGRÁFICAS*}

1 ADES, A. G. et al. A long-term study of the relationship of the third molars to changes in the mandibular dental arch. Amer. J. Orthodont. Dentofac. Orthod., v.97, n.4, p.323-35, Apr. 1990.

2 ANDREWS, L. F. The diagnostic system: occlusal analysis. Dent. Clin. N. Amer. v.20, p.671-90, 1976.

3 AZAZ, B.; TAICHER, S. Indications for removal of the mandibular impacted third molar. J. Canad. dent. Ass., v.48, n.11, p.731-4, Nov. 1982.

4 BERGSTRON, K.; JENSEN, R. Responsability of the third molar for secondary crowding. Dent. Abstr. (Chicago.), v.6, n.9 ,p.544-5, Sept. 1961.

5 BERTKOWITZ, B. K. B. et al. A colour atlas \& textbook of oral anatomy. London, Wolfe Medical Publ., 1977. p.36-7.

6 BISHARA, S. E.; ANDREANSEN, G. Third molars: A review. Amer. J. Orthodont., v.83,n.2,p.131-7, Feb. 1983.

\footnotetext{
* Normas recomendadas para o uso no âmbito da Universidade da São Paulo, com base no documento "Referências Bibliográficas: exemplos", emanado do Conselho Supervisor do Sistema Integrado de Bibliotecas da USP, em reunião de 20 de setembro de 1990.
} 
7 BJÖRK, A.; SKIELLER, V. Facial development and tooth eruption. Am. Implant study at the age of puberty. Amer. J. Orthodont., v.62, n.4, p.33983, Oct. 1972.

8 BJÖRK, A. J.; ELLI, P. M. Mandibular growth and third molar impaction. Acta odont. scand., v.14, p.231-72, 1956.

9 BLACKMAN, S. Mass dental radiography. Radiography, v.22, p.22-5, 1956.

10 BROADBENT, B. H. The influence of the third molars on the alignment of the teeth. Amer. J. Orthodont., v.29, n.4, p.312-30, June 1943.

11 CHACONAS, S. J. Orthodontics. Massachusetts, PSG Publishing Company, 1980. p.265-73.

12 CHIPMAN, M. S. Third molar eruption and the effect of extration of adjecent teeth. Dent. Pract., v.47, n.7, p.498-520, July 1961.

13 COHEN, M. E. et al. Age - specific angulation of unerupted human third molar teeth in a cross - sectional sample. Oral Arch Biol., v.30, n.5, p.441-4, May 1985.

14 DACHI, S. F.; HOWELL, F. V. A survey of 3874 routine full-month radiographs. A study of impacted teeth. Oral Surg., v.10, n.14, p.1165-9, Oct. 1961.

15 DAHLBERG, G. Statistical methods for medical and biological students. New York, Interscience, 1940. 
16 DEWEL, B. F. Clinical observations on the axial inclination of teeth. Amer. J. Orthodont., v.62, p.296-309, 1949.

17 DIERKES, D. D. An investigation of the mandibular third molars in orthodontic cases. Angle Orthodont., v.45, n.3, p.207-12, July 1975.

18 ENGSTRÖM, C. et al. Lower third molar development in relation to skeletal maturity and chronological age. Angle Orthodont. v.53, n.2, p.97-106, Apr. 1983.

19 ENLOW, D. H. Crescimento facial. 3.ed. São Paulo, Artes Médicas. $3^{\mathrm{a}}$ ed. 1993. 553p.

20 FAnNing, E. A. third molar emergence in bostonians. Amer. J. Phys. Anthrop., v.20, n.3, p.339-45, Sept. 1962.

21 FERNANDES, A. F. C. Análise de movimento mesial dos primeiros molares permanentes inferiores, em casos de maloclusão Classe I, biprotrusão, tratados com extrações dos primeiros pré-molares. Rio de Janeiro, 1978. 44p. Dissertação (Mestrado) - Faculdade de Odontologia da U.F.R.J.

22 FIGUN, M. E.; GARINO, R. R. Anatomia odontológica funcional y aplicada. $2^{\mathrm{a}}$ ed. Buenos Aires, El Ateneo, 1986. 518p.

23 FORD, J. W. The unerupted third molar from an orthodontic poit of view. J. Amer. dent. Ass., v.27, n.12, p.1863-72, Dec. 1940.

24 FRIEDMAN, J. W. The case for preservation of third molars. J. Calif. dent. Ass., v.5, n.5, p.50-6, May. 1977. 
25 GARN, S.; LEWIS, A. B.; BONNÉ, B. Third molar formation and its development couse. Angle Orthodont ., v.32, n.4 p.270-9, Oct. 1962.

26 GARN, S. M.; LEWWIS, A. B. The relationship between third molar agenesis and reduction in tooth nember. Angle Orthodont., v.32, n.1, p.14-18, Jan.1962.

27 GILBERT, S. G. Orthodontics and the panorex $\mathbf{X}$ - ray. Bull. Philadelphia Co. dent. Soc., v.28, p.11-15, 1962.

28 GOBliRsCH, A.W. A study of the third molar teeth. J. Amer. dent. Ass., Chicago, v.17, n.10, p.1849-54, Oct. 1930.

29 GRABER, T. M. Orthodontics, principles and practice. 2 ed. Philadelphia, W. B. Saundrs Company, 1961. 805p.

30 GRABER, T. M. Postmortemsin posttreatment adjustments. Amer. J. Orthodont., v. 52, p.311-52, 1976.

31 GRABER, T. M.; KAINEG, T.F. The mandibular third molar - its predictive status and role in lower incisor crowding. Proc. Finn. Dent. Soc., v.77, p.37-44, 1981.

32 GRANDINI, S. A. et al. Estudos da incidência dos dentes inclusos - Pesquisa através do exame radiográfico de 1.000 pacientes. Rev. Ass. paul. cirurg. Dent., v.20, n.3, p.90-8, maio/jun. 1966. 
33 HAAVIKKO, K.; ALTONEN, M.; MATTILA, k. Predicting angulation development and eruption of the lower third molar. Angle Orthodont., v.48, n.1, p.39-48, Jan. 1978.

34 HELLMAN, M. Our third molar teeth, their eruption, presence and absence. Dent. Cosmos., v.78, n.7, p.750-62, July. 1936.

35 HELlman, M. Some aspects of wisdom teeth and their impactions. Arch. Clin. Oral Path., v.2, n.2, p.125-41, June 1938.

36 HENRY, C. B.; MORANT, G. M. A preliminary study of the eruption of the mandibular third molar tooth in man based on measurement obtained to the problem of predictiong cases of ultimate impactions of the tooth. Biométrica, London, v.28, n.3-4, p.378-426, Dec.1936.

37 HILLIN, G. R. Indications for the removal of impacted third molars at na early age. Amer. J. Orthodont. oral Surg., St. Louis, v.33, n.5, p.302-7, May 1947.

38 HOEK, R. B. Third molars. J. Am. dent. Ass., Chicago, v.68, n.4, p.541-8, Apr. 1964.

39 HOUStOn, W. J. B. Analysis of erro inorthodontics measurements. Amer. J. Orthodont., v.82, n.6, p.464-8, Dec. 1983.

40 ISHIKAWA, F. et al. Orthodontic applications of panoramic radiography with panorex. J. Jap. Ortho dont. Soc., v.27, p.151-6, 1968. 
41 KRAMER, R. M.; WILliAN, A . C. The incidence of impacted teeth. Oral Surg., v.29, n.2, p.237-41, Feb. 1970.

42 KAPLAN, R. G. Mandibular third molars and posretention crowding. Amer. J. Orthodont., v.66, n.4, p.411-30, Oct. 1974.

43 KEENE, H. J. Third molar agenesis apacing and crowding of teeth, and tooth size in caries - resistant naval recruits. Amer. J. Orthodont., v.50, n.6, p.445-51, Jun. 1964.

44 LASKIN, D. M. Indications and contraindications for removal of impacted third molars. Dent. Clin. N. Amer., v.13, n.4, p.916-28, Oct. 1969.

45 LASKIN, D. M. Evaluation of the third molar problem. J. Amer. dent. Ass., v.82, n.4, p.824-8, Apr. 1971.

46 LEDYARD JÚNIOR.; B. C. A study of the mandibular third molar area. Amer. J. Orthodont., v.39, n.5, p.366-73, May 1953.

47 LIDDLE, D. W. Second molar extration in orthodontic treatment. Amer. J. Orthodont., v.72, n.6, p.599-616, Dec. 1977.

48 LINDQUIST, B.; THIRLANDER, B. Extraction of third molars in cases of anticipated crowding in the lower jaw. Amer. J. Orthodont., v.81, n.2, p.130-9, Feb. 1982.

49 LYTLE, J. J. Indications and contraindications for removal of the impacted tooth. Dent. Clin. N. Amer., v.23, n.3, p.333-46, July 1979. 
50 LUND, T. M.; MANSON-HING, L. R. Relations between tooth position and focal throughs of panoramic machines. Oral Surg., v.40, p.285-93, 1975.

51 McCOY, J. R. A study of growth potencial Amer. J. Orthodont., v.51, n.2, p.79-97, Feb. 1965.

52 MitChell, L. D. Panoramic roentgenografhy. J. Amer. dent. Ass., v.66, p.777-86, 1963.

53 MLYNARSKA - ZDUANIAK, E. Angles of inclination of the axes of teeth and the buds of permanent teeth in pantomograms in normal occlusion in the early period of tooth exchange. Czas. Stomat., v.36, p.541-6, 1983.

54 MERRIFIELD, L.L. Differencial diagnosis with total apace analyses. Charles H. Tweed Found. J., v.6, n.1, p.10-15, Mar.1978.

55 MOYERS, R.E. Orthodontia. 4.ed. Rio de Janeiro, Guanabara Koogan, 1988. $483 p$.

56 NANDA, R.S. Agenesis of the third molar in man. Amer. J. Orthodont ., v.40, n.9, p.698-706, Sept. 1954.

57 NANDA, R.S. Status of third molar teeth. J. All-India Dent. Ass., v.31, n.2, p.19-29, Feb. 1959.

58 NIH Consensus development Conference for removal third molars. J. oral Surg. v.38, n.3, p.235-6, Mar. 1980. 
59 PAATERO, Y.V. A new tomographical mathod for radiographing curve outer surfaces. Acta Radiol., v.32, p.177-84, 1949.

60 PAIVA, A.L. Orthodontia preventiva básica. São Paulo, Artes Médicas, 1990. $168 \mathrm{p}$.

61 PERLOW, J. A full light-arch technique utilizing Bull's principles of extrations treatment with emphasis on twenty-eight teeth. Amer. J. Orthodont., v.50, n.2, p.81-98, Feb. 1964.

62 PICOSSE, M. Anatomia dentária. São Paulo, Sarvier, 1971. p.207-8.

63 QUINN, G.W. Extraction of four second molars. Angle Orthodont ., v.55, n.1, p.58-69, Jan. 1985.

64 RANTANEN, A. The age of eruption of third molar teeth. Acta odont. scand., 25(suppl. 48), p.8-80, 1967.

65 RICHARDSON, M.E. The etiology and prediction of mandibular third molar impaction. Angle Orthodont., v.47, n.3, p.165-72. July 1977.

66 RICHARDSON, M.E. Pre-eruptive movements of the mandibular third molar. Angle Orthodont ., v.48, n.3, p.187-93, July 1978.

67 RICHARDSON, M.E. Late third molar agenesis: its significance in orthodontic treatment. Angle Orthodont., v.50, n.2, p.121-8, Apr. 1980.

68 RICHARDSON, M.E. Late lower arch crowding in relation to primary crowding. Angle Orthodont., v.52, n.4, p.300-12. Oct. 1982. 
69 RICHARDSON, E.R.; MALHOTRA, S.; SEMENYA, K. Longitudinal study of three views of mandibular third molar eruption in males. Amer. J. Orthodont., v.86, n.2, p.119-29, Aug. 1984.

70 RICHARDSON, M.E. Lower third molar space. Angle Orthodont., v.57, n.2, p.155-61, Apr.1987.

71 RICKETTS, R.M. A principal of racial growth of the mandible. Angle Orthodont., v.42, n.4, p.368-86, Oct. 1972.

72 RICKETTS, R.M. et al. Third molar enucleation: diagnósis and tecnique. J. Calif. dent. Ass., v.4, n.4, p.52-7, Apr. 1976.

73 RICKETTS, R.M. Studies leading to the practice of abortion of lower third molars. Dent. Clin J. Amer., v.23, n.3, p.393-411, July 1979.

74 ROTHEMBERG, F. The lowwer third molar problem. Amer. J. Orthodont., v.31, n.2, p.104-15, Feb. 1945.

75 SCHULHOF, R.J. Third molar enucleation: diagnosis and tecnique. J. Calif. dent. Ass., p.52-7, 1976.

76 SHAW, F. Impacted mandibular third molars. Brit. dent. J., v.124, n.6, p.278, June 1968 .

77 SICHER, H. The growth of the mandible. Amer. J. Orthodont., v.33, n.1, p.305, Jan. 1947. 
78 SICHER, H.; DUBRUL, E.L. Oral anatomy. 5 ed. Saint Louis, Mosby, 1970. p.261-2.

79 STAGGERS, J.A.; GERMANE, N.; FORTSON, W.M. A comparison of the effects of first premolar extrations on third molar angulation. Angle Orthodont., v.62, n.2, p.135-8, Summer 1992.

80 STEINER, C.C. The use of cephalometrics as na aid to planning and assessing orthodontic treatment. Amer. J. Orthodont., v.46, n.10, p.721-35, Oct. 1960.

81 STEINER, C.C. Cephalome trics as a clinical tool. In: KRAUS; RIEDEL, org. Vistas in Orthodontics. Philadelphia, Lea \& Febiger, 1962. p.131-61.

82 STRANG, R.H.W. A textbook of orthodontia. 3. ed. Philadelphia, Lea e Febiger, 1950. 824p.

83 TAVANO, O. et al. Determinação das linhas de referência para medições angulares em radiografias ortopantomográficas. Odont. Mod., v.16, n.9, p.22-5, set. 1989 .

84 TWEED, C.H. Indication for extraction of teeth in orthodontic procedures. Amer. J. Orthodont. oral Surg., v.30, p.405-28, 1944.

85 THUROW, R.C.E. A third molar is not a mountain. Angle Orthodont., v.52, n.4, p.262-3, Oct. 1982.

86 URSI, W.J.S. Avaliação das inclinações axiais mesiodistais dos dentes superiores e inferiores, em uma amostra de oclusão normal, não tratada 
ortodonticamente, utilizando radiografias ortopantomográficas obtidas em diferentes aparelhos. São Paulo, 1989. 99p. Dissertação (Mestrado) Faculdade de Odontologia de Bauru, Universidade de São Paulo.

87 WHEELER, R.C. Textbook of dental anatomy and physiology. 4.ed. Philadelphia, Saunders, 1965. p.381-6.

88 VEGO, L.R. A longitudinal study of mandibular arch perimeter. Angle Orthodont., v.32, n.3, p.187-92, July 1962.

89 WEInStein, S. Third molar impactions in orthodontics. J. Amer. dent Ass., v.82,n.4, p.819-23, Apr. 1971.

90 WILLIS, T.A. The impacted mandibular molar. Angle Orthodont., v.36, n.2, p.165-8, Apr. 1966. 
Abstract 


\begin{abstract}
CLINICAL PRESENCE AND ANGULATION OF THE THIRD UPPER MOLARS, IN BAD CLASS II OCCLUSION, POOR WITH AND WITHOUT UPPER PREMOLAR EXTRACTIONS
\end{abstract}

The objective of this project is to compare the corrent number of third upper molars, in funnction, among Class II patients, treated dentally, with and without extractionsof two upper bicuspids. To do as much, 55 patients were selected and divided into two groups. Group 1, treated without extractions, was made up of 28 patients with na average age of 19,03 (the youngest age was 14,08 and the oldest was 23,92), and group 2, having been treated with extractions, was composed of 27 patients with na average age of 19,94 (the youngest age was 14,75 and the oldest being 25,67). To verify the eruption of occlusion of the third molars, upper and lower plaster molds of the last control of the dentally-treated groups were used. Additionally, evaluations of the axial mesion-distal angulations of the third upper molars were made, employing orthopantographic radiographs of the last control, with the bilateral presence of the third molars. The axial angulations of the third molars were measured in relation to the orbits and tuberosities inboth groups and were compared. To compare the number of erupted third upper molars and in function of both groups, the chi-square test was utilized. To compare the angulations of the third molars among the groups, the independentet-test was used. The results demonstrated that the amount of erupted third upper molars (and in function) was statistically 
greater inthe cases treated with extractions of the upper bicuspids than in the cases treated without extractions, and that the mesion-distal angulations were statistically lower and morefavorable to the same, respectively. Therefore, one can expect that the result of the positioning of the third upper molars in the poor occlusion of Class II, when conducted with two bicuspid extractions, will be better than when effected without two upper bicuspids extractions. 
Apêndice 
As tabelas A - 1 a A - 12 referem-se aos valores reais individuais de cada variável, para cada paciente, do grupo 1 e 2 .

Tabela A - 1

\begin{tabular}{|c|c|c|c|c|c|c|c|c|c|c|c|}
\hline Nome & Núm. & Arquivo & Grupo & Idade início trat. & $\begin{array}{c}\text { Idade início trat. } \\
\text { (dec.) }\end{array}$ & Data início trat. & $\begin{array}{l}\text { Data término } \\
\text { trat. }\end{array}$ & $\begin{array}{c}\text { Tempo do } \\
\text { Tratam. }\end{array}$ & $\begin{array}{l}\text { Tempo do } \\
\text { Tratam. (dec.) }\end{array}$ & $\begin{array}{l}\text { Idade térm. } \\
\text { Tratam. (dec.) }\end{array}$ & 10. contr. \\
\hline A. L. B. & 1 & $30 \mathrm{D} 4$ & 1 & $13 \mathrm{a}$ & 13,00 & $20 / 11 / 73$ & $25 / 02 / 76$ & $02 \mathrm{a} 04 \mathrm{~m}$ & 2,33 & 15,33 & $16 / 03 / 77$ \\
\hline J. G. T. W. & 2 & $63 \mathrm{~S} 9$ & 1 & $13 \mathrm{a} 02 \mathrm{~m}$ & 13,17 & $29 / 01 / 76$ & $15 / 03 / 77$ & $01 \mathrm{a} 02 \mathrm{~m}$ & 1,17 & 14,34 & $18 / 09 / 78$ \\
\hline A. S. S. & 3 & 84 D8 & 1 & $11 \mathrm{a} 09 \mathrm{~m}$ & 11,75 & $16 / 12 / 75$ & $17 / 12 / 76$ & $01 \mathrm{a}$ & 1,00 & 12,75 & $21 / 03 / 78$ \\
\hline J. Y. A. & 4 & 86 D7 & 1 & $12 \mathrm{a} 08 \mathrm{~m}$ & 12,67 & 25/03/76 & $31 / 05 / 77$ & 01a $03 \mathrm{~m}$ & 1,25 & 13,92 & 13/06/78 \\
\hline E.D. Z. & 5 & 93 F12 & 1 & $12 \mathrm{a} 08 \mathrm{~m}$ & 12,67 & $20 / 06 / 77$ & $14 / 02 / 79$ & $01 \mathrm{a} 08 \mathrm{~m}$ & 1,67 & 14,34 & $14 / 04 / 80$ \\
\hline M. M. M. & 6 & $102 \mathrm{M} 11$ & 1 & $14 \mathrm{a} 02 \mathrm{~m}$ & 14,17 & $27 / 06 / 77$ & $29 / 06 / 79$ & $02 \mathrm{a} 01 \mathrm{~m}$ & 2,08 & 16,25 & $26 / 08 / 80$ \\
\hline I. B. & 7 & $140 \mathrm{~F} 17$ & 1 & $13 \mathrm{a} 09 \mathrm{~m}$ & 13,75 & $29 / 09 / 79$ & $16 / 06 / 81$ & $01 \mathrm{a} 09 \mathrm{~m}$ & 1,75 & 15,50 & $30 / 07 / 82$ \\
\hline M. A C. & 8 & $144 \mathrm{C} 16$ & 1 & $12 \mathrm{a} 02 \mathrm{~m}$ & 12,17 & $26 / 06 / 79$ & $17 / 02 / 81$ & $01 \mathrm{a} 08 \mathrm{~m}$ & 1,67 & 13,84 & $20 / 07 / 82$ \\
\hline E.M. & 9 & $153 \mathrm{C} 18$ & 1 & $12 \mathrm{a} 04 \mathrm{~m}$ & 12,34 & $03 / 07 / 79$ & $10 / 05 / 82$ & $02 \mathrm{a} 11 \mathrm{~m}$ & 2,92 & 15,26 & $19 / 05 / 83$ \\
\hline A. L. B. & 10 & $158 \mathrm{M} 18$ & 1 & $14 \mathrm{a} 05 \mathrm{~m}$ & 14,42 & $21 / 06 / 79$ & $22 / 12 / 81$ & $02 \mathrm{a} 07 \mathrm{~m}$ & 2,58 & 17,00 & $22 / 12 / 82$ \\
\hline A. A. G. & 11 & 282 G34 & 1 & $13 \mathrm{a} 05 \mathrm{~m}$ & 13,42 & $02 / 07 / 86$ & $16 / 05 / 88$ & $01 \mathrm{a} 11 \mathrm{~m}$ & 1,92 & 15,34 & 29/06/89 \\
\hline A. L. A. & 12 & 296 C 36 & 1 & 12a 06m & 12,50 & $07 / 07 / 86$ & $25 / 04 / 88$ & 01a 10m & 1,83 & 14,33 & $15 / 03 / 89$ \\
\hline V.P.P. & 13 & 362 D43 & 1 & $12 \mathrm{a} 02 \mathrm{~m}$ & 12,17 & $31 / 08 / 89$ & $23 / 03 / 94$ & $04 \mathrm{a} 07 \mathrm{~m}$ & 4,58 & 16,75 & $03 / 07 / 96$ \\
\hline A. P. D. & 14 & 373 F45 & 1 & $11 \mathrm{a} 03 \mathrm{~m}$ & 11,25 & $14 / 06 / 89$ & $30 / 05 / 00$ & $11 \mathrm{a}$ & 11,00 & 22,25 & \\
\hline L. J. C. & 15 & $399 \mathrm{~F} 48$ & 1 & $13 \mathrm{a} 03 \mathrm{~m}$ & 13,25 & $10 / 09 / 89$ & $04 / 04 / 91$ & $01 \mathrm{a} 07 \mathrm{~m}$ & 1,58 & 14,83 & $26 / 05 / 92$ \\
\hline F. M. A. & 16 & $410 \mathrm{~A} 50$ & 1 & 12a 06m & 12,50 & $14 / 06 / 89$ & $27 / 08 / 91$ & $02 \mathrm{a} 03 \mathrm{~m}$ & 2,25 & 14,75 & $01 / 12 / 92$ \\
\hline T. C. M. & 17 & 459 A54 & 1 & $10 \mathrm{a} 05 \mathrm{~m}$ & 10,42 & $03 / 11 / 92$ & 07/03/95 & $02 \mathrm{a} 05 \mathrm{~m}$ & 2,42 & 12,84 & $17 / 05 / 96$ \\
\hline V. O J. & 18 & 479 M56 & 1 & $10 \mathrm{a} 09 \mathrm{~m}$ & 10,75 & $15 / 06 / 92$ & $19 / 11 / 96$ & $04 \mathrm{a} 06 \mathrm{~m}$ & 4,50 & 15,25 & $26 / 04 / 97$ \\
\hline R. C. B. & 19 & 491 G57 & 1 & $13 a$ & 13,00 & $16 / 11 / 92$ & $01 / 05 / 95$ & 02a 06m & 4,50 & 17,50 & 06/07/01 \\
\hline A. A. C. & 20 & 534 F62 & 1 & $12 \mathrm{a} 07 \mathrm{~m}$ & 12,58 & $20 / 10 / 92$ & $24 / 10 / 95$ & $03 \mathrm{a} 01 \mathrm{~m}$ & 3,08 & 15,66 & \\
\hline
\end{tabular}




\section{Tabela A-2}

\begin{tabular}{|c|c|c|c|c|c|c|c|c|c|c|c|}
\hline C. C. B. & 21 & $538 \mathrm{~F} 62$ & 1 & $11 \mathrm{a} 04 \mathrm{~m}$ & 11,33 & $26 / 10 / 92$ & $30 / 08 / 94$ & $01 \mathrm{a} 11 \mathrm{~m}$ & 1,92 & 13,25 & $03 / 07 / 96$ \\
\hline V. L. V. V. & 22 & 552 A63 & 1 & $13 \mathrm{a} 02 \mathrm{~m}$ & 13,17 & 09/06/92 & $18 / 08 / 96$ & $04 \mathrm{a} 03 \mathrm{~m}$ & 4,25 & 17,42 & $17 / 09 / 97$ \\
\hline L. G. R. I. & 23 & 601 F67 & 1 & $14 \mathrm{a} 01 \mathrm{~m}$ & 14,08 & $29 / 10 / 93$ & $03 / 12 / 96$ & $03 \mathrm{a} 02 \mathrm{~m}$ & 3,17 & 17,25 & \\
\hline D. R. C. & 24 & 629 F71 & 1 & $13 \mathrm{a} 05 \mathrm{~m}$ & 13,42 & $24 / 11 / 95$ & $16 / 10 / 98$ & $02 \mathrm{a} 11 \mathrm{~m}$ & 2,92 & 16,34 & $10 / 11 / 99$ \\
\hline G. F. & 25 & $640 \mathrm{M} 72$ & 1 & $11 \mathrm{a} 09 \mathrm{~m}$ & 11,75 & 07/11/95 & 03/03/98 & $02 \mathrm{a} 04 \mathrm{~m}$ & 2,33 & 14,08 & $30 / 03 / 99$ \\
\hline R.H.C. & 26 & 644 A72 & 1 & $13 \mathrm{a} 04 \mathrm{~m}$ & 13,33 & $18 / 09 / 95$ & $05 / 05 / 98$ & 02a 08m & 2,67 & 16,00 & $=$ \\
\hline A. M. N. & 27 & $646 \mathrm{~A} 73$ & 1 & $12 \mathrm{a} 08 \mathrm{~m}$ & 12,67 & $19 / 09 / 95$ & $17 / 10 / 97$ & $02 \mathrm{a} 01 \mathrm{~m}$ & 2,08 & 14,75 & $01 / 06 / 99$ \\
\hline R. M. A. & 28 & $721 \mathrm{G} 64$ & 1 & 09a $08 \mathrm{~m}$ & 9,67 & $15 / 04 / 93$ & $24 / 09 / 96$ & 03a 06m & 3,50 & 13,17 & $19 / 06 / 97$ \\
\hline A. B. J. & 29 & - & 2 & $15 \mathrm{a}$ & 15,00 & $12 / 04 / 91$ & $11 / 10 / 95$ & 04a 06m & 4,50 & 19,50 & $11 / 10 / 97$ \\
\hline R. Z. C. & 30 & 80 D5 & 2 & $14 \mathrm{a} 08 \mathrm{~m}$ & 14,67 & $04 / 09 / 78$ & $06 / 04 / 82$ & 03a $08 \mathrm{~m}$ & 3,67 & 18,34 & $05 / 04 / 83$ \\
\hline R.F.F. & 31 & 99 M14 & 2 & $13 \mathrm{a} 02 \mathrm{~m}$ & 13,17 & $20 / 06 / 77$ & $01 / 12 / 82$ & 05a 06m & 5,50 & 18,67 & $=$ \\
\hline J. R. G. A. & 32 & 137 F18 & 2 & $14 \mathrm{a} 10 \mathrm{~m}$ & 14,83 & $26 / 06 / 79$ & $23 / 12 / 81$ & 02a 06m & 2,50 & 17,33 & $17 / 03 / 83$ \\
\hline W. B. & 33 & $141 \mathrm{D} 17$ & 2 & $13 a$ & 13,00 & $06 / 06 / 79$ & $06 / 04 / 82$ & 02a $10 \mathrm{~m}$ & 2,83 & 15,83 & $15 / 03 / 83$ \\
\hline A. P. L. & 34 & $143 \mathrm{D} 18$ & 2 & 12a $10 \mathrm{~m}$ & 12,83 & $28 / 06 / 79$ & $07 / 06 / 82$ & $03 \mathrm{a}$ & 3,00 & 15,83 & $27 / 09 / 83$ \\
\hline M.P.P. & 35 & 217 F22 & 2 & $19 \mathrm{a}$ & 19,00 & $29 / 04 / 83$ & $22 / 04 / 84$ & 01a & 1,00 & 20,00 & $02 / 12 / 85$ \\
\hline A. C. & 36 & $218 \mathrm{M} 28$ & 2 & 14a $07 \mathrm{~m}$ & 14,58 & $06 / 06 / 83$ & $12 / 09 / 85$ & 02a $04 \mathrm{~m}$ & 2,33 & 16,91 & $26 / 02 / 87$ \\
\hline G. C. N. & 37 & $222 \mathrm{C} 28$ & 2 & $12 \mathrm{a} 06 \mathrm{~m}$ & 12,50 & $16 / 08 / 83$ & $15 / 12 / 84$ & 01a $05 \mathrm{~m}$ & 1,42 & 13,92 & $12 / 05 / 86$ \\
\hline L. F. N. & 38 & 233 F29 & 2 & $11 \mathrm{a} 09 \mathrm{~m}$ & 11,75 & $04 / 04 / 83$ & $17 / 06 / 86$ & 03a 03m & 3,25 & 15,00 & $31 / 08 / 87$ \\
\hline C. L. & 39 & $241 \mathrm{C} 30$ & 2 & 12a $11 \mathrm{~m}$ & 12,92 & $20 / 06 / 83$ & $05 / 08 / 87$ & 04a $02 \mathrm{~m}$ & 4,17 & 17,09 & $23 / 08 / 88$ \\
\hline R. M. C. & 40 & $256 \mathrm{M} 31$ & 2 & $13 \mathrm{a} 10 \mathrm{~m}$ & 13,83 & 07/07/83 & $18 / 12 / 85$ & 02a 06m & 2,50 & 16,33 & $12 / 12 / 86$ \\
\hline A. S. A. & 41 & 265 F32 & 2 & $15 \mathrm{a} 06 \mathrm{~m}$ & 15,50 & $07 / 07 / 83$ & $22 / 11 / 85$ & 02a $05 \mathrm{~m}$ & 2,42 & 17,92 & $17 / 10 / 86$ \\
\hline M. T. & 42 & $270 \mathrm{~A} 22$ & 2 & $16 \mathrm{a} 02 \mathrm{~m}$ & 16,17 & $03 / 10 / 83$ & $05 / 02 / 86$ & $02 \mathrm{a} 05 \mathrm{~m}$ & 2,42 & 18,59 & $18 / 02 / 87$ \\
\hline A. B. & 43 & $271 \mathrm{~A} 30$ & 2 & $13 \mathrm{a} 09 \mathrm{~m}$ & 13,75 & $25 / 03 / 84$ & $03 / 12 / 86$ & 02a 09m & 2,75 & 16,50 & $01 / 03 / 88$ \\
\hline I. G. & 44 & 278 A 34 & 2 & $17 \mathrm{a} 07 \mathrm{~m}$ & 17,58 & $26 / 06 / 86$ & $14 / 12 / 88$ & 02a 06m & 2,50 & 20,08 & $13 / 12 / 89$ \\
\hline L. F. M. & 45 & 303 M37 & 2 & $16 \mathrm{a} 01 \mathrm{~m}$ & 16,08 & $11 / 07 / 86$ & $26 / 04 / 88$ & 01a 10m & 1,83 & 17,91 & $06 / 08 / 89$ \\
\hline L. C. & 46 & $324 \mathrm{M} 40$ & 2 & $14 \mathrm{a} 09 \mathrm{~m}$ & 14,75 & $10 / 07 / 86$ & $01 / 06 / 88$ & 01a $11 \mathrm{~m}$ & 1,92 & 16,67 & $20 / 06 / 89$ \\
\hline
\end{tabular}


Tabela A-3

\begin{tabular}{l|c|l|c|c|c|c|c|c|c|c|c}
\hline \hline L. O. & 47 & $334 \mathrm{M} 42$ & 2 & $13 \mathrm{a} 11 \mathrm{~m}$ & 13,92 & $03 / 07 / 86$ & $03 / 08 / 88$ & $02 \mathrm{a} 01 \mathrm{~m}$ & 2,08 & 16,00 & $24 / 08 / 89$ \\
\hline W. F. & 48 & $343 \mathrm{~A} 40$ & 2 & $15 \mathrm{a} 03 \mathrm{~m}$ & 15,25 & $12 / 09 / 86$ & $02 / 05 / 89$ & $02 \mathrm{a} 08 \mathrm{~m}$ & 2,67 & 17,92 & $05 / 07 / 90$ \\
\hline C. F. P. & 49 & $352 \mathrm{G} 42$ & 2 & $09 \mathrm{a} 05 \mathrm{~m}$ & 9,42 & $16 / 04 / 88$ & $20 / 03 / 94$ & $05 \mathrm{a} 11 \mathrm{~m}$ & 5,92 & 15,34 & $28 / 03 / 95$ \\
\hline M. Z. C. & 50 & $486 \mathrm{E} 57$ & 2 & $12 \mathrm{a} 02 \mathrm{~m}$ & 12,00 & $04 / 12 / 92$ & $05 / 06 / 96$ & $03 \mathrm{a} 07 \mathrm{~m}$ & 3,58 & 15,58 & $17 / 09 / 97$ \\
\hline C. S. Z. & 51 & $498 \mathrm{M} 58$ & 2 & $11 \mathrm{a} 04 \mathrm{~m}$ & 11,33 & $15 / 09 / 92$ & $06 / 07 / 94$ & $01 \mathrm{a} 10 \mathrm{~m}$ & 1,83 & 13,16 & $02 / 05 / 95$ \\
\hline P. S. O. & 52 & $530 \mathrm{G} 61$ & 2 & $16 \mathrm{a} 02 \mathrm{~m}$ & 16,17 & $26 / 10 / 92$ & $30 / 06 / 95$ & $02 \mathrm{a} 09 \mathrm{~m}$ & 2,75 & 18,92 & -- \\
\hline R. C. & 53 & $573 \mathrm{G} 65$ & 2 & $10 \mathrm{a} 08 \mathrm{~m}$ & 10,67 & $15 / 09 / 92$ & $28 / 03 / 96$ & $03 \mathrm{a} 07 \mathrm{~m}$ & 3,58 & 14,25 & - \\
\hline E. B. & 54 & $638 \mathrm{~F} 72$ & 2 & $16 \mathrm{a} 04 \mathrm{~m}$ & 16,33 & $19 / 09 / 95$ & $22 / 02 / 00$ & $04 \mathrm{a} 06 \mathrm{~m}$ & 4,50 & 20,83 & $19 / 10 / 01$ \\
\hline M. R. M. & 55 & $710 \mathrm{G} 58$ & 2 & $12 \mathrm{a} 05 \mathrm{~m}$ & 12,42 & $31 / 03 / 95$ & $30 / 06 / 97$ & $02 \mathrm{a} 04 \mathrm{~m}$ & 2,33 & 14,75 & $25 / 11 / 00$ \\
\hline \hline
\end{tabular}




\section{Tabela A-4}

\begin{tabular}{|c|c|c|c|c|c|c|c|c|c|c|c|}
\hline Nome & Núm. & Grupo & 2o. contr. & 3o. contr. & 4o. contr. & 5o. contr. & 10o.cont. & $\begin{array}{l}\text { Último controle } \\
\text { c/ 3o. Molar }\end{array}$ & $\begin{array}{c}\text { Tempo controle } \\
\text { c/ 3o. Molar }\end{array}$ & $\begin{array}{l}\text { Tp. cont. c/ 3o. } \\
\text { Molar (dec) }\end{array}$ & $\begin{array}{l}\text { Idade últ. } \\
\text { controle c/ } 30 . \\
\text { Mol.(dec) } \\
\end{array}$ \\
\hline A. L. B. & 1 & 1 & & $1 / 12 / 79$ & & $21 / 01 / 81$ & & $21 / 01 / 81$ & $07 \mathrm{a} 03 \mathrm{~m}$ & 7,25 & 20,25 \\
\hline J. G. T. W. & 2 & 1 & - & - & $27 / 01 / 81$ & $11 / 06 / 82$ & 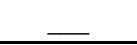 & $11 / 06 / 82$ & 06a $05 \mathrm{~m}$ & 7,42 & 20,59 \\
\hline A. S. S. & 3 & 1 & $19 / 12 / 79$ & $17 / 12 / 80$ & $09 / 02 / 81$ & $22 / 12 / 81$ & $\overline{ }$ & $22 / 12 / 81$ & 06a 01m & 6,08 & 17,83 \\
\hline J. Y. A. & 4 & 1 & $06 / 07 / 79$ & $15 / 07 / 80$ & 08/07/81 & $31 / 08 / 82$ & $=$ & $15 / 07 / 80$ & $04 \mathrm{a} 04 \mathrm{~m}$ & 4,33 & 17,00 \\
\hline E.D. Z. & 5 & 1 & $10 / 04 / 81$ & $09 / 03 / 82$ & $15 / 04 / 83$ & $27 / 08 / 84$ & $\overline{.}$ & $27 / 08 / 84$ & $07 \mathrm{a} 03 \mathrm{~m}$ & 7,25 & 19,92 \\
\hline M. M. M. & 6 & 1 & $08 / 12 / 81$ & $07 / 02 / 83$ & $11 / 07 / 83$ & $25 / 10 / 84$ & 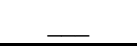 & $07 / 02 / 83$ & 05a $08 \mathrm{~m}$ & 5,67 & 19,84 \\
\hline I. B. & 7 & 1 & $04 / 07 / 83$ & $27 / 06 / 84$ & $07 / 06 / 85$ & $17 / 06 / 86$ & $\bar{L}$ & $17 / 06 / 86$ & 06a 09m & 6,75 & 20,50 \\
\hline M. A C. & 8 & 1 & $20 / 05 / 83$ & $17 / 05 / 84$ & $24 / 05 / 85$ & $21 / 08 / 86$ & $\bar{z}$ & $21 / 08 / 86$ & $07 \mathrm{a} 02 \mathrm{~m}$ & 7,17 & 19,34 \\
\hline E. M. & 9 & 1 & $16 / 05 / 84$ & $10 / 06 / 85$ & $20 / 05 / 86$ & $28 / 05 / 87$ & $=$ & $28 / 05 / 87$ & $07 \mathrm{a} 11 \mathrm{~m}$ & 7,92 & 20,26 \\
\hline A. L. B. & 10 & 1 & $11 / 11 / 83$ & $17 / 12 / 84$ & $03 / 02 / 86$ & - & 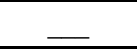 & $22 / 12 / 82$ & 03a 07m & 3,58 & 18,00 \\
\hline A. A. G. & 11 & 1 & $05 / 06 / 90$ & $05 / 06 / 91$ & $09 / 10 / 92$ & $04 / 10 / 93$ & 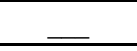 & $04 / 10 / 93$ & $07 \mathrm{a} 04 \mathrm{~m}$ & 7,33 & 20,75 \\
\hline A. L. A. & 12 & 1 & $01 / 04 / 90$ & $\overline{\bar{L}}$ & $08 / 04 / 92$ & $17 / 05 / 93$ & $\bar{L}$ & $17 / 05 / 93$ & 06a 11m & 6,92 & 19,42 \\
\hline V.P.P. & 13 & 1 & $15 / 09 / 99$ & $\bar{L}$ & - & $19 / 02 / 02$ & $\bar{\tau}$ & $23 / 03 / 94$ & 04a 07m & 4,58 & 16,75 \\
\hline A. P. D. & 14 & 1 & 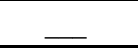 & - & 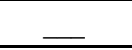 & $30 / 05 / 00$ & $=$ & $30 / 05 / 00$ & $11 \mathrm{a}$ & 11,00 & 22,25 \\
\hline L. J. C. & 15 & 1 & $21 / 05 / 93$ & $12 / 12 / 94$ & $=$ & $06 / 03 / 97$ & 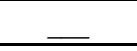 & $12 / 12 / 94$ & 05a $04 \mathrm{~m}$ & 5,33 & 18,58 \\
\hline F. M. A. & 16 & 1 & $08 / 11 / 93$ & $14 / 12 / 94$ & 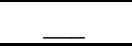 & $30 / 10 / 00$ & 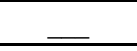 & $30 / 10 / 00$ & $11 \mathrm{a} 05 \mathrm{~m}$ & 11,42 & 23,92 \\
\hline T. C. M. & 17 & 1 & $22 / 09 / 97$ & $11 / 08 / 99$ & $\overline{-}$ & $=$ & $\overline{-}$ & $11 / 08 / 99$ & 06a 10m & 6,83 & 17,25 \\
\hline V. O J. & 18 & 1 & $10 / 11 / 98$ & $12 / 04 / 00$ & 工 & 09/11/01 & $\bar{L}$ & $09 / 11 / 01$ & 09a 05m & 9,42 & 20,17 \\
\hline R. C. B. & 19 & 1 & $=$ & 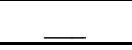 & $=$ & $08 / 12 / 01$ & $=$ & $08 / 12 / 01$ & 09a 01m & 9,08 & 22,08 \\
\hline A. A. C. & 20 & 1 & $=$ & $=$ & $=$ & $=$ & 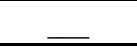 & $24 / 10 / 95$ & 03a $01 \mathrm{~m}$ & 3,08 & 15,66 \\
\hline C. C. B. & 21 & 1 & - & $17 / 06 / 98$ & $\overline{-}$ & $09 / 04 / 00$ & 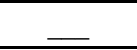 & $17 / 06 / 98$ & 05a $08 \mathrm{~m}$ & 5,67 & 17,00 \\
\hline V. L. V. V. & 22 & 1 & $17 / 11 / 98$ & $16 / 11 / 99$ & $\overline{-}$ & $16 / 10 / 01$ & $\bar{\tau}$ & $16 / 10 / 01$ & 09a 05m & 9,42 & 22,59 \\
\hline L. G. R. I. & 23 & 1 & & & & & & $03 / 12 / 96$ & 03a $02 \mathrm{~m}$ & 3,17 & 17,25 \\
\hline
\end{tabular}


Tabela A-5

\begin{tabular}{|c|c|c|c|c|c|c|c|c|c|c|c|}
\hline D. R. C. & 24 & 1 & - & 09/11/01 & - & $16 / 01 / 02$ & - & $09 / 11 / 01$ & $06 a$ & 6,00 & 19,42 \\
\hline G. F. & 25 & 1 & - & $20 / 11 / 01$ & - & $15 / 01 / 02$ & - & 03/03/98 & 02a $04 \mathrm{~m}$ & 2,33 & 14,08 \\
\hline R.H.C. & 26 & 1 & - & 06/07/01 & - & - & - & 06/07/01 & 05a 10m & 5,83 & 19,16 \\
\hline A. M. N. & 27 & 1 & - & $15 / 01 / 02$ & - & - & - & $17 / 10 / 97$ & 02a $01 \mathrm{~m}$ & 2,08 & 14,75 \\
\hline R. M. A. & 28 & 1 & $12 / 11 / 98$ & $01 / 02 / 00$ & - & $07 / 12 / 01$ & - & $07 / 12 / 01$ & 08a 08m & 8,67 & 18,34 \\
\hline A. B. J. & 29 & 2 & - & - & - & - & - & $11 / 10 / 95$ & 04a 06m & 4,50 & 19,50 \\
\hline R. Z. C. & 30 & 2 & - & $13 / 12 / 85$ & $24 / 12 / 86$ & - & - & $04 / 09 / 78$ & $01 \mathrm{~m}$ & 0,08 & 14,75 \\
\hline R. F. F. & 31 & 2 & $12 / 12 / 84$ & $23 / 12 / 85$ & $08 / 12 / 86$ & $09 / 12 / 87$ & - & $09 / 12 / 87$ & $10 \mathrm{a} 06 \mathrm{~m}$ & 10,50 & 23,67 \\
\hline $\begin{array}{l}\text { J. R. G. } \\
\text { A. }\end{array}$ & 32 & 2 & $08 / 03 / 84$ & $12 / 02 / 85$ & $07 / 04 / 86$ & $26 / 06 / 87$ & - & $26 / 06 / 87$ & $08 \mathrm{a}$ & 8,00 & 22,83 \\
\hline W. B. & 33 & 2 & - & $18 / 06 / 85$ & - & - & - & $18 / 06 / 85$ & $06 a$ & 6,00 & 19,00 \\
\hline A. P. L. & 34 & 2 & $16 / 08 / 84$ & $02 / 09 / 85$ & - & - & - & $02 / 09 / 85$ & 06a 03m & 6,25 & 19,08 \\
\hline M.P.P. & 35 & 2 & $26 / 03 / 87$ & $03 / 12 / 87$ & $13 / 12 / 88$ & $13 / 12 / 89$ & - & $13 / 12 / 89$ & 06a 08m & 6,67 & 25,67 \\
\hline A. C. & 36 & 2 & $04 / 03 / 88$ & $09 / 03 / 89$ & - & - & - & $09 / 03 / 89$ & 05a $10 \mathrm{~m}$ & 5,83 & 20,41 \\
\hline G. C. N. & 37 & 2 & $22 / 05 / 87$ & $19 / 05 / 88$ & $05 / 05 / 90$ & 03/06/91 & - & $19 / 05 / 88$ & 04a 10m & 4,83 & 17,33 \\
\hline L. F. N. & 38 & 2 & $09 / 05 / 88$ & 04/10/89 & 02/03/91 & - & $06 / 09 / 96$ & 02/03/91 & 07a $11 \mathrm{~m}$ & 7,92 & 19,67 \\
\hline C. L. & 39 & 2 & - & - & - & - & - & $23 / 08 / 88$ & 05a 03m & 5,25 & 18,17 \\
\hline R. M. C. & 40 & 2 & $07 / 12 / 87$ & $07 / 12 / 88$ & - & - & $23 / 11 / 93$ & $23 / 11 / 93$ & $10 \mathrm{a} 05 \mathrm{~m}$ & 10,42 & 24,25 \\
\hline A. S. A. & 41 & 2 & $17 / 11 / 87$ & $21 / 11 / 88$ & $07 / 11 / 89$ & $13 / 12 / 90$ & - & $07 / 07 / 83$ & $01 \mathrm{~m}$ & 0,08 & 15,58 \\
\hline M. T. & 42 & 2 & - & - & - & - & - & $18 / 02 / 87$ & 03a $05 \mathrm{~m}$ & 3,42 & 19,59 \\
\hline A. B. & 43 & 2 & $04 / 04 / 89$ & 03/10/93 & $15 / 08 / 95$ & - & - & $01 / 03 / 88$ & 03a $11 \mathrm{~m}$ & 3,92 & 17,67 \\
\hline I. G. & 44 & 2 & $13 / 12 / 90$ & $12 / 12 / 91$ & - & - & - & $12 / 12 / 91$ & 05a 06m & 5,50 & 23,08 \\
\hline L. F. M. & 45 & 2 & $20 / 08 / 90$ & $12 / 07 / 91$ & - & $24 / 06 / 93$ & - & $26 / 04 / 88$ & 01a 10m & 1,83 & 17,91 \\
\hline L. C. & 46 & 2 & $08 / 12 / 92$ & - & - & - & - & $08 / 12 / 92$ & 06a 05m & 6,42 & 21,17 \\
\hline L. O. & 47 & 2 & $20 / 08 / 90$ & $15 / 01 / 92$ & 08/03/93 & - & - & $08 / 03 / 93$ & 06a 09m & 6,75 & 20,67 \\
\hline W. F. & 48 & 2 & $05 / 11 / 91$ & $08 / 12 / 92$ & - & $20 / 05 / 94$ & $13 / 12 / 94$ & $20 / 05 / 94$ & 07a 09m & 7,75 & 23,00 \\
\hline C. F. P. & 49 & 2 & $27 / 10 / 97$ & - & - & $15 / 03 / 02$ & - & $27 / 10 / 97$ & 09a 07m & 9,58 & 19,00 \\
\hline
\end{tabular}


Tabela A-6

\begin{tabular}{l|c|c|c|c|c|c|c|c|c|c|c}
\hline \hline M. Z. C. & 50 & 2 & - & - & - & $12 / 10 / 01$ & - & $12 / 10 / 01$ & $08 \mathrm{a} 11 \mathrm{~m}$ & 8,92 & 20,92 \\
\hline C. S. Z. & 51 & 2 & - & $01 / 10 / 97$ & - & $09 / 11 / 99$ & - & $01 / 10 / 97$ & $05 \mathrm{a} 01 \mathrm{~m}$ & 5,08 & 16,41 \\
\hline P. S. O. & 52 & 2 & - & $09 / 06 / 00$ & - & $09 / 04 / 01$ & - & $09 / 04 / 01$ & $08 \mathrm{a} 06 \mathrm{~m}$ & 8,50 & 24,67 \\
\hline R. C. & 53 & 2 & - & $18 / 06 / 99$ & - & $10 / 12 / 01$ & - & $10 / 12 / 01$ & $09 \mathrm{a} 03 \mathrm{~m}$ & 9,25 & 19,92 \\
\hline E. B. & 54 & 2 & - & - & - & - & - & $19 / 09 / 95$ & $01 \mathrm{~m}$ & 0,08 & 16,41 \\
\hline M. R. M. & 55 & 2 & - & $16 / 01 / 02$ & - & - & - & $25 / 11 / 00$ & $05 \mathrm{a} 08 \mathrm{~m}$ & 5,67 & 18,09 \\
\hline \hline
\end{tabular}


Tabela A-7

\begin{tabular}{|c|c|c|c|c|c|c|c|c|c|c|c|c|}
\hline Nome & Núm. & Grupo & $\begin{array}{c}\text { Tempo xp } \\
3^{\circ} \mathrm{m} \text {. até } \\
\text { último } \\
\text { controle }\end{array}$ & $\begin{array}{c}\text { Idade } \\
\text { último } \\
\text { controle c/ } \\
\text { ou s/ } 3^{\circ} \\
\text { molar } \\
\end{array}$ & Cl. MD & Cl. ME & Arquiv. & 3MSD Orbita & 3MSE Orbita & $\begin{array}{c}\text { Média da Orbita } \\
\text { direita e esq. }\end{array}$ & $\begin{array}{c}\text { Média da } \\
\text { Orbita e Maxila } \\
\text { direita }\end{array}$ & 3MSD Maxila \\
\hline A. L. B. & 1 & 1 & 0,00 & 20,25 & Compl. & Compl. & $30 \mathrm{D} 4$ & 124 & 117 & 120,5 & 124 & 124 \\
\hline J. G. T. W. & 2 & 1 & 0,00 & 20,59 & $1 / 2$ & $1 / 2$ & $63 \mathrm{~S} 9$ & & & & & 117 \\
\hline A. S. S. & 3 & 1 & 0,00 & 17,83 & Compl. & Compl. & 84D8 & & & & & 102 \\
\hline J. Y. A. & 4 & 1 & 2,08 & 19,08 & $1 / 2$ & $1 / 2$ & $86 \mathrm{D} 7$ & 118 & 128 & 123 & 116,5 & 115 \\
\hline E.D. Z. & 5 & 1 & 0,00 & 19,92 & $1 / 2$ & $1 / 2$ & $93 \mathrm{~F} 12$ & & & & & 148 \\
\hline M. M. M. & 6 & 1 & 1,66 & 21,50 & Compl. & Compl. & 102M11 & 114 & 142 & 128 & 115,5 & 117 \\
\hline I. B. & 7 & 1 & 0,00 & 20,50 & $1 / 2$ & $1 / 2$ & $140 \mathrm{~F} 17$ & 124 & 124 & 124 & 124 & 124 \\
\hline M. A C. & 8 & 1 & 0,00 & 19,34 & Compl. & Compl. & $144 \mathrm{C} 16$ & & & & & 125 \\
\hline E.M. & 9 & 1 & 0,00 & 20,26 & Compl. & Compl. & 153D18 & 117 & 121 & 119 & 115,5 & 114 \\
\hline A. L. B. & 10 & 1 & 3,08 & 21,08 & Compl. & $1 / 2$ & 158M18 & & & & & 99 \\
\hline A. A. G. & 11 & 1 & 0,00 & 20,75 & Compl. & $1 / 2$ & $282 \mathrm{G} 34$ & 156 & 128 & 142 & 159 & 162 \\
\hline A. L. A. & 12 & 1 & 0,00 & 19,42 & Compl. & $1 / 2$ & $296 \mathrm{C} 36$ & 89 & 94 & 91,5 & 89,5 & 90 \\
\hline V.P.P. & 13 & 1 & 7,33 & 24,08 & $1 / 2$ & Compl. & 362D43 & 152 & 123 & 137,5 & 152 & 152 \\
\hline A. P. D. & 14 & 1 & 0,00 & 22,25 & Compl. & Compl. & $373 F 45$ & 119 & 103 & 111 & 116,5 & 114 \\
\hline L. J.C. & 15 & 1 & 2,25 & 20,83 & $1 / 2$ & $1 / 2$ & $399 \mathrm{~F} 48$ & 118 & 115 & 116,5 & 118 & 118 \\
\hline F. M. A. & 16 & 1 & 0,00 & 23,92 & $1 / 2$ & Compl. & 410A50 & 114 & 115 & 114,5 & 113 & 112 \\
\hline T. C. M. & 17 & 1 & 0,00 & 17,25 & Compl. & $1 / 2$ & 459A54 & 114 & 107 & 110,5 & 114 & 114 \\
\hline V. O J. & 18 & 1 & 0,00 & 20,17 & Compl. & Compl. & 479M56 & 115 & 119 & 117 & 116,5 & 118 \\
\hline R. C. B. & 19 & 1 & 0,00 & 22,08 & $1 / 2$ & $1 / 2$ & 491G57 & 123 & 113 & 118 & 123,5 & 124 \\
\hline A. A. C. & 20 & 1 & 0,00 & 15,66 & Compl. & $1 / 2$ & 534F00 & 113 & 138 & 125,5 & 113,5 & 114 \\
\hline C. C. B. & 21 & 1 & 1,83 & 18,83 & $1 / 2$ & $1 / 2$ & $538 \mathrm{~F} 62$ & 107 & 98 & 102,5 & 117,5 & 108 \\
\hline
\end{tabular}


Tabela A-8

\begin{tabular}{|c|c|c|c|c|c|c|c|c|c|c|c|c|}
\hline V. L. V. V. & 22 & 1 & 0,00 & 22,59 & Compl. & Compl. & $552 \mathrm{~A} 63$ & 110 & 125 & 117,5 & 110 & 110 \\
\hline L. G. R. I. & 23 & 1 & 0,00 & 17,25 & Compl. & Compl. & $601 \mathrm{~F} 67$ & 119 & 135 & 127 & 118,5 & 118 \\
\hline D. R. C. & 24 & 1 & 0,25 & 19,67 & Compl. & $1 / 2$ & $629 \mathrm{~F} 71$ & 119 & 127 & 123 & 119 & 119 \\
\hline G. F. & 25 & 1 & 3,84 & 17,92 & $1 / 2$ & $1 / 2$ & 640M72 & 121 & 118 & 119,5 & 120,5 & 120 \\
\hline R.H.C. & 26 & 1 & 0,00 & 19,16 & Compl. & Compl. & $644 \mathrm{~A} 72$ & 114 & 93 & 103,5 & 113 & 112 \\
\hline A. M. N. & 27 & 1 & 4,42 & 19,17 & $1 / 2$ & $1 / 2$ & $646 \mathrm{~A} 73$ & 130 & 131 & 103,5 & 130 & 131 \\
\hline R. M. A. & 28 & 1 & 0,00 & 18,34 & Compl. & Compl. & $721 \mathrm{G} 64$ & 110 & 122 & 116 & 110,5 & 111 \\
\hline A. B. J. & 29 & 2 & 2,00 & 21,50 & Compl. & Compl. & 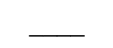 & 91 & 99 & 95 & 91 & 91 \\
\hline R. Z. C. & 30 & 2 & 8,42 & 23,17 & Compl. & Compl. & 80D5 & 108 & 128 & 118 & 108,5 & 109 \\
\hline R. F. F. & 31 & 2 & 0,00 & 23,67 & Compl. & Compl. & 99M14 & 123 & 116 & 119,5 & 124 & 125 \\
\hline J. R. G. A. & 32 & 2 & 0,00 & 22,83 & Compl. & Compl. & 137F18 & 119 & 135 & 127 & 119 & 119 \\
\hline W. B. & 33 & 2 & 0,00 & 19,00 & Compl. & Compl. & 141D17 & 105 & 98 & 101,5 & 105 & 105 \\
\hline A. P. L. & 34 & 2 & 0,00 & 19,08 & Compl. & Compl. & 143D18 & 102 & 112 & 107 & 103,5 & 105 \\
\hline M.P.P. & 35 & 2 & 0,00 & 25,67 & Compl. & Compl. & $217 \mathrm{~F} 22$ & 104 & 98 & 101 & 103,5 & 103 \\
\hline A. C. & 36 & 2 & 0,00 & 20,41 & Compl. & $1 / 2$ & $218 \mathrm{M} 28$ & 95 & 105 & 100 & 96 & 97 \\
\hline G. C. N. & 37 & 2 & 3,09 & 20,42 & $1 / 2$ & $1 / 2$ & $222 \mathrm{C} 28$ & 106 & 116 & 111 & 107 & 108 \\
\hline L. F. N. & 38 & 2 & 5,66 & 25,33 & $1 / 2$ & Compl. & $233 \mathrm{~F} 29$ & 105 & 116 & 110,5 & 107 & 109 \\
\hline C. L. & 39 & 2 & 0,00 & 18,17 & Compl. & Compl. & $241 \mathrm{C} 30$ & 109 & 118 & 113,5 & 109 & 110 \\
\hline R. M. C. & 40 & 2 & 0,00 & 24,25 & Compl. & Compl. & 256M31 & 147 & 111 & 129 & 146,5 & 146 \\
\hline A. S. A. & 41 & 2 & 7,59 & 23,17 & Compl. & $1 / 2$ & $265 \mathrm{~F} 32$ & & & & & 57 \\
\hline M. T. & 42 & 2 & 0,00 & 19,59 & $1 / 2$ & $1 / 2$ & $270 \mathrm{~A} 22$ & & & & & 118 \\
\hline A. B. & 43 & 2 & 7,58 & 25,25 & Compl. & Compl. & 271A30 & 113 & 109 & 111 & 112,5 & 112 \\
\hline I. G. & 44 & 2 & 0,00 & 23,08 & Compl. & Compl. & $278 \mathrm{~A} 34$ & 100 & 90 & 80 & 99,5 & 99 \\
\hline
\end{tabular}


Tabela A-9

\begin{tabular}{l|c|c|c|c|c|c|c|c|c|c|c|c}
\hline \hline L. F. M. & 45 & 2 & 5,17 & 23,08 & $1 / 2$ & $1 / 2$ & $303 \mathrm{M} 37$ & 119 & 112 & 115,5 & 120 & 121 \\
\hline L. C. & 46 & 2 & 0,00 & 21,17 & Compl. & $1 / 2$ & $324 \mathrm{M} 40$ & 110 & 123 & 116,5 & 110,5 & 111 \\
\hline L. O. & 47 & 2 & 0,00 & 20,67 & Compl. & Compl. & $334 \mathrm{~F} 00$ & 120 & 108 & 114 & 119 & 118 \\
\hline W. F. & 48 & 2 & 0,00 & 23,00 & Compl. & Compl. & $343 \mathrm{~A} 40$ & 107 & 114 & 110,5 & 106 & 105 \\
\hline C. F. P. & 49 & 2 & 4,42 & 23,42 & Compl. & Compl. & $352 \mathrm{G} 42$ & 97 & 96 & 96,5 & 97,5 & 98 \\
\hline M.Z. C. & 50 & 2 & 0,00 & 20,92 & $1 / 2$ & $1 / 2$ & $486 \mathrm{G} 57$ & 115 & 101 & 108 & 115 & 115 \\
\hline C. S. Z. & 51 & 2 & 2,09 & 18,50 & $1 / 2$ & Compl. & $498 \mathrm{M} 58$ & 140 & 134 & 137 & 138,5 & 137 \\
\hline P. S. O. & 52 & 2 & 0,00 & 24,67 & Compl. & $1 / 2$ & $530 \mathrm{G} 61$ & 120 & 106 & 113 & 119,5 & 119 \\
\hline R. C. & 53 & 2 & 0,00 & 19,92 & Compl. & Compl. & $573 \mathrm{G} 65$ & 110 & 112 & 111 & 109,5 & 109 \\
\hline E. B. & 54 & 2 & 6,09 & 22,50 & Compl. & Compl. & $638 \mathrm{~F} 00$ & 107 & 117 & 112 & 106 & 105 \\
\hline M. R. M. & 55 & 2 & 1,16 & 19,25 & $1 / 2$ & $1 / 2$ & $710 \mathrm{G} 58$ & 111 & 108 & 109,5 & 109,5 & 108 \\
\hline \hline
\end{tabular}


Tabela A-10

\begin{tabular}{|c|c|c|c|c|c|c|c|c|c|c|c|c|c|}
\hline Nome & Núm. & Grupo & $\begin{array}{l}\text { 3MSE } \\
\text { Maxila }\end{array}$ & $\begin{array}{c}\text { Média da } \\
\text { Maxila } \\
\text { direita e } \\
\text { esq. } \\
\end{array}$ & $\begin{array}{c}\text { Média da } \\
\text { Orbita e } \\
\text { Maxila esq. }\end{array}$ & $\begin{array}{l}\text { 3MID } \\
\text { Mand. }\end{array}$ & $\begin{array}{l}\text { 3MIE } \\
\text { Mand. }\end{array}$ & $\begin{array}{c}\text { Média } \\
\text { mand. } \\
\text { Direita e } \\
\text { esq. } \\
\end{array}$ & $3^{\circ}$ MSD & $3^{\circ}$ MSE & $3^{\circ} \mathrm{MID}$ & $3^{\circ} \mathrm{MIE}$ & $\begin{array}{c}\text { Posição dos } 3^{\text {os }} \\
\text { molares }\end{array}$ \\
\hline A. L. B. & 1 & 1 & 118 & 121 & 117,5 & & 47 & & Com Rx Sem m. & Com Rx Sem m. & Sem Rx & Com Rx Sem m. & \\
\hline J. G. T. W. & 2 & 1 & 132 & 124,5 & & 60 & 61 & 60,5 & Com m. & Com m. & Com Rx Sem m. & Com Rx Sem m. & supra irromp. \\
\hline A. S. S. & 3 & 1 & 124 & 113 & & 56 & 43 & 49,5 & Com Rx Sem m. & Com Rx Sem m. & Com Rx Sem m. & Com Rx Sem m. & - \\
\hline J. Y. A. & 4 & 1 & 129 & 122 & 128,5 & 59 & 26 & 42,5 & Com Rx Sem m. & Com Rx Sem m. & Com Rx Sem m. & Com Rx Sem m. & \\
\hline E.D. Z. & 5 & 1 & 136 & 142 & & 73 & 64 & 35,5 & Com m. & Com m. & Com m. & Com m. & em função \\
\hline M. M. M. & 6 & 1 & 139 & 128 & 140,5 & 21 & 21 & 21 & Com Rx Sem m. & Com Rx Sem m. & $\begin{array}{c}\text { Com Rx Com } \\
\mathrm{m} .\end{array}$ & Sem Rx & - \\
\hline I. B. & 7 & 1 & 123 & 123,5 & 123,5 & -9 & 180 & 85,5 & Com Rx Sem m. & Com Rx Sem m. & Com Rx Sem m. & Com Rx Sem m. & $=$ \\
\hline M. A C. & 8 & 1 & 142 & 133,5 & & 24 & 35 & 29,5 & Com Rx Sem m. & Com Rx Sem m. & Com Rx Sem m. & Com Rx Sem m. & - \\
\hline E. M. & 9 & 1 & 123 & 118,5 & 122 & 180 & 44 & 112 & Com Rx Sem m. & Com Rx Sem m. & Com Rx Sem m. & Com Rx Sem m. & - \\
\hline A. L. B. & 10 & 1 & 124 & 111,5 & & 59 & 45 & 52 & Com m. & Com Rx Sem m. & $\begin{array}{c}\text { Com Rx Com } \\
\mathrm{m} .\end{array}$ & Com Rx Sem m. & sem função \\
\hline A. A. G. & 11 & 1 & 122 & 142 & 125 & 22 & 29 & 25,5 & Com Rx Sem m. & Com Rx Sem m. & Com Rx Sem m. & Com Rx Sem m. & 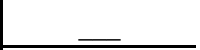 \\
\hline A. L. A. & 12 & 1 & 92 & 91 & 93 & 64 & 62 & 63 & Com m. & Com m. & Com Rx Sem m. & Com Rx Sem m. & em função \\
\hline V.P.P. & 13 & 1 & 123 & 137,5 & 123 & -7 & 30 & 10,5 & Com Rx Sem m. & Com Rx Sem m. & Com rx Sem m. & Com Rx Sem m. & \\
\hline A.P. D. & 14 & 1 & 109 & 111,5 & 106 & & 180 & & Com Rx Sem m. & Com Rx Sem m. & Sem Rx & Com Rx Sem m. & \\
\hline L. J. C. & 15 & 1 & 116 & 117 & 115,5 & 58 & 67 & 62,5 & Com m. & Com m. & Com m. & Com m. & em função \\
\hline F. M. A. & 16 & 1 & 117 & 114,5 & 116 & -7 & -13 & -10 & Com Rx Sem m. & Com Rx Sem m. & Com Rx Sem m. & Com Rx Sem m. & $=$ \\
\hline T. C. M. & 17 & 1 & 106 & 110 & 106,5 & 70 & 74 & 72 & Com m. & Com m. & Com m. & Com m. & em função \\
\hline V. O J. & 18 & 1 & 116 & 117 & 117,5 & 47 & 84 & 65,5 & Com Rx Sem m. & Com Rx Sem m. & Com Rx Sem m. & Com Rx Sem m. & \\
\hline
\end{tabular}


Tabela A-11

\begin{tabular}{|c|c|c|c|c|c|c|c|c|c|c|c|c|c|}
\hline R. C. B. & 19 & 1 & 112 & 118 & 112,5 & & 68 & & Com m. & Com m. & Sem Rx & Com m. & $\begin{array}{l}\text { função } \\
\text { lado } \\
\text { erq. }\end{array}$ \\
\hline AA C. & 20 & 1 & 136 & 125 & 137 & 51 & 38 & 44,5 & $\begin{array}{l}\text { Com Rx } \\
\text { Sem m. }\end{array}$ & $\begin{array}{l}\text { Com Rx } \\
\text { Sem m. }\end{array}$ & $\begin{array}{l}\text { Com Rx } \\
\text { Sem m. }\end{array}$ & $\begin{array}{l}\text { Com Rx } \\
\text { Sem m. }\end{array}$ & - \\
\hline C. C. B. & 21 & 1 & 98 & 103 & 98 & 47 & 47 & 47 & $\begin{array}{l}\text { Com Rx } \\
\text { Sem m. }\end{array}$ & $\begin{array}{l}\text { Com Rx } \\
\text { Sem m. }\end{array}$ & $\begin{array}{l}\text { Com Rx } \\
\text { Sem m. }\end{array}$ & $\begin{array}{l}\text { Com Rx } \\
\text { Sem m. }\end{array}$ & - \\
\hline $\begin{array}{l}\text { V. L. V. } \\
\text { V. }\end{array}$ & 22 & 1 & 125 & 117,5 & 125 & 75 & 71 & 73 & $\begin{array}{l}\text { Com Rx } \\
\text { Sem m. }\end{array}$ & Com m. & Com m. & Com m. & - \\
\hline $\begin{array}{l}\text { L. G. R. } \\
\text { I. }\end{array}$ & 23 & 1 & 135 & 126,5 & 135 & 33 & 60 & 46,5 & $\begin{array}{l}\text { Com Rx } \\
\text { Sem m. }\end{array}$ & $\begin{array}{l}\text { Com Rx } \\
\text { Sem m. }\end{array}$ & $\begin{array}{l}\text { Com Rx } \\
\text { Sem m. }\end{array}$ & $\begin{array}{l}\text { Com Rx } \\
\text { Sem m. }\end{array}$ & - \\
\hline D. R. C. & 24 & 1 & 126 & 122,5 & 126,5 & 39 & 32 & 35,5 & $\begin{array}{l}\text { Com Rx } \\
\text { Sem m. }\end{array}$ & $\begin{array}{l}\text { Com Rx } \\
\text { Sem m. }\end{array}$ & $\begin{array}{l}\text { Com Rx } \\
\text { Sem m. }\end{array}$ & $\begin{array}{l}\text { Com Rx } \\
\text { Sem m. }\end{array}$ & - \\
\hline G. F. & 25 & 1 & 118 & 119 & 118 & 44 & 53 & 48,5 & $\begin{array}{l}\text { Com Rx } \\
\text { Sem m. }\end{array}$ & $\begin{array}{l}\text { Com Rx } \\
\text { Sem m. }\end{array}$ & $\begin{array}{l}\text { Com Rx } \\
\text { Sem m. }\end{array}$ & $\begin{array}{l}\text { Com Rx } \\
\text { Sem m. }\end{array}$ & - \\
\hline R.H.C. & 26 & 1 & 96 & 104 & 94,5 & 6 & 13 & 9,5 & $\begin{array}{l}\text { Com Rx } \\
\text { Sem m. }\end{array}$ & $\begin{array}{l}\text { Com Rx } \\
\text { Sem m. }\end{array}$ & $\begin{array}{l}\text { Com Rx } \\
\text { Sem m. }\end{array}$ & $\begin{array}{l}\text { Com Rx } \\
\text { Sem m. }\end{array}$ & - \\
\hline $\begin{array}{l}\text { A. M. } \\
\text { N. }\end{array}$ & 27 & 1 & 130 & 130,5 & 130,5 & 51 & 58 & 54,4 & $\begin{array}{l}\text { Com Rx } \\
\text { Sem m. }\end{array}$ & $\begin{array}{l}\text { Com Rx } \\
\text { Sem m. }\end{array}$ & $\begin{array}{l}\text { Com Rx } \\
\text { Sem m. }\end{array}$ & $\begin{array}{l}\text { Com Rx } \\
\text { Sem m. }\end{array}$ & - \\
\hline $\begin{array}{l}\text { R. M. } \\
\text { A. }\end{array}$ & 28 & 1 & 121 & 116 & 121,5 & 47 & 37 & 42 & $\begin{array}{l}\text { Com Rx } \\
\text { Sem m. }\end{array}$ & $\begin{array}{l}\text { Com Rx } \\
\text { Sem m. }\end{array}$ & $\begin{array}{l}\text { Com Rx } \\
\text { Sem m. }\end{array}$ & $\begin{array}{l}\text { Com Rx } \\
\text { Sem m. }\end{array}$ & - \\
\hline A. B. J. & 29 & 2 & 99 & 95 & 99 & 62 & 60 & 61 & Com m. & Com m. & $\begin{array}{l}\text { Com Rx } \\
\text { Sem m. }\end{array}$ & $\begin{array}{l}\text { Com Rx } \\
\text { Sem m. }\end{array}$ & $\begin{array}{l}\text { supra } \\
\text { irromp. }\end{array}$ \\
\hline R. Z. C. & 30 & 2 & 127 & 118 & 127,5 & & & & $\begin{array}{l}\text { Com Rx } \\
\text { Sem m. }\end{array}$ & $\begin{array}{l}\text { Com Rx } \\
\text { Sem m. }\end{array}$ & $\begin{array}{l}\text { Com Rx } \\
\text { Sem m. }\end{array}$ & $\begin{array}{l}\text { Com Rx } \\
\text { Sem m. }\end{array}$ & - \\
\hline R. F. F. & 31 & 2 & 114 & 119,5 & 115 & & 48 & & $\begin{array}{l}\text { Com Rx } \\
\text { Sem m. }\end{array}$ & $\begin{array}{l}\text { Com Rx } \\
\text { Sem m. }\end{array}$ & $\begin{array}{l}\text { Com Rx } \\
\text { Sem m. }\end{array}$ & $\begin{array}{l}\text { Com Rx } \\
\text { Sem m. }\end{array}$ & - \\
\hline $\begin{array}{l}\text { J. R. G. } \\
\text { A. }\end{array}$ & 32 & 2 & 135 & 127 & 135 & & & & Com m. & Com m. & Sem Rx & Sem Rx & $\begin{array}{l}\text { sem } \\
\text { função }\end{array}$ \\
\hline W. B. & 33 & 2 & 98 & 101,5 & 98 & 10 & 180 & 95 & Com m. & Com m. & $\begin{array}{l}\text { Com Rx } \\
\text { Sem m. }\end{array}$ & $\begin{array}{l}\text { Com Rx } \\
\text { Sem m. }\end{array}$ & $\begin{array}{l}\text { em } \\
\text { função }\end{array}$ \\
\hline A. P. L. & 34 & 2 & 110 & 107,5 & 111 & 50 & 52 & 51 & Com m. & Com m. & $\begin{array}{l}\text { Com Rx } \\
\text { Sem m. }\end{array}$ & $\begin{array}{l}\text { Com Rx } \\
\text { Sem m. }\end{array}$ & $\begin{array}{l}\text { supra } \\
\text { irromp. }\end{array}$ \\
\hline M.P.P. & 35 & 2 & 99 & 101 & 98,5 & 73 & & & Com m. & Com m. & Com m. & Sem Rx & $\begin{array}{l}\text { em } \\
\text { função }\end{array}$ \\
\hline A. C. & 36 & 2 & 102 & 99,5 & 103,5 & 71 & 50 & 60,5 & $\begin{array}{l}\text { Com Rx } \\
\text { Sem m. }\end{array}$ & $\begin{array}{l}\text { Com Rx } \\
\text { Sem m. }\end{array}$ & $\begin{array}{l}\text { Com Rx } \\
\text { Sem m. }\end{array}$ & $\begin{array}{l}\text { Com Rx } \\
\text { Sem m. }\end{array}$ & - \\
\hline G. C. N. & 37 & 2 & 114 & 111 & 115 & 69 & 57 & 63 & $\begin{array}{l}\text { Com Rx } \\
\text { Sem m. }\end{array}$ & $\begin{array}{l}\text { Com Rx } \\
\text { Sem m. }\end{array}$ & $\begin{array}{l}\text { Com Rx } \\
\text { Sem m. }\end{array}$ & $\begin{array}{l}\text { Com Rx } \\
\text { Sem m. }\end{array}$ & - \\
\hline L. F. N. & 38 & 2 & 112 & 110,5 & 114 & 43 & 25 & 34 & $\begin{array}{l}\text { Com Rx } \\
\text { Sem m. }\end{array}$ & $\begin{array}{l}\text { Com Rx } \\
\text { Sem m. }\end{array}$ & $\begin{array}{l}\text { Com Rx } \\
\text { Sem m. }\end{array}$ & $\begin{array}{l}\text { Com Rx } \\
\text { Sem m. }\end{array}$ & - \\
\hline
\end{tabular}


Tabela A-12

\begin{tabular}{|c|c|c|c|c|c|c|c|c|c|c|c|c|c|}
\hline C. L. & 39 & 2 & 119 & 114,5 & 118,5 & 54 & 60 & 57 & $\begin{array}{l}\text { Com Rx } \\
\text { Sem m. }\end{array}$ & $\begin{array}{l}\text { Com Rx } \\
\text { Sem m. }\end{array}$ & $\begin{array}{l}\text { Com Rx } \\
\text { Sem m. }\end{array}$ & $\begin{array}{l}\text { Com Rx } \\
\text { Sem m. }\end{array}$ & - \\
\hline $\begin{array}{l}\text { R. M. } \\
\text { C. }\end{array}$ & 40 & 2 & 112 & 129 & 111,5 & 63 & 56 & 59,5 & $\begin{array}{l}\text { Com Rx } \\
\text { Sem m. }\end{array}$ & $\begin{array}{l}\text { Com Rx } \\
\text { Sem m. }\end{array}$ & $\begin{array}{c}\text { Com Rx } \\
\text { Sem m. }\end{array}$ & $\begin{array}{l}\text { Com Rx } \\
\text { Sem m. }\end{array}$ & - \\
\hline A. S. A. & 41 & 2 & 89 & 73 & & 43 & 33 & 38 & $\begin{array}{l}\text { Com Rx } \\
\text { Sem m. }\end{array}$ & $\begin{array}{l}\text { Com Rx } \\
\text { Sem m. }\end{array}$ & Sem Rx & Sem Rx & - \\
\hline M. T. & 42 & 2 & 130 & 124 & & 41 & 41 & 41 & $\begin{array}{l}\text { Com Rx } \\
\text { Sem m. }\end{array}$ & $\begin{array}{l}\text { Com Rx } \\
\text { Sem m. }\end{array}$ & $\begin{array}{l}\text { Com Rx } \\
\text { Sem m. }\end{array}$ & $\begin{array}{l}\text { Com Rx } \\
\text { Sem m. }\end{array}$ & - \\
\hline A. B. & 43 & 2 & 109 & 110,5 & 109 & 180 & -9 & 86 & $\begin{array}{l}\text { Com Rx } \\
\text { Sem m. }\end{array}$ & $\begin{array}{l}\text { Com Rx } \\
\text { Sem m. }\end{array}$ & $\begin{array}{l}\text { Com Rx } \\
\text { Sem m. }\end{array}$ & $\begin{array}{l}\text { Com Rx } \\
\text { Sem m. }\end{array}$ & - \\
\hline I. G. & 44 & 2 & 91 & 95 & 90,5 & & & & Com m. & Com m. & Sem Rx & Sem Rx & $\begin{array}{c}\text { em } \\
\text { função }\end{array}$ \\
\hline L. F. M. & 45 & 2 & 111 & 116 & 111,5 & 74 & 61 & 67,5 & $\begin{array}{l}\text { Com Rx } \\
\text { Sem m. }\end{array}$ & $\begin{array}{l}\text { Com Rx } \\
\text { Sem m. }\end{array}$ & Sem Rx & $\begin{array}{l}\text { Com Rx } \\
\text { Sem m. }\end{array}$ & - \\
\hline L. C. & 46 & 2 & 122 & 116,5 & 122,5 & 71 & 67 & 69 & $\begin{array}{l}\text { Com Rx } \\
\text { Sem m. }\end{array}$ & $\begin{array}{l}\text { Com Rx } \\
\text { Sem m. }\end{array}$ & $\begin{array}{l}\text { Com Rx } \\
\text { Sem m. }\end{array}$ & $\begin{array}{l}\text { Com Rx } \\
\text { Sem m. }\end{array}$ & - \\
\hline L. O. & 47 & 2 & 111 & 114,5 & 109,5 & 57 & 56 & 56,5 & Com m. & Com m. & $\begin{array}{l}\text { Com Rx } \\
\text { Sem m. }\end{array}$ & $\begin{array}{l}\text { Com Rx } \\
\text { Sem m. }\end{array}$ & $\begin{array}{l}\text { supra } \\
\text { irromp. }\end{array}$ \\
\hline W. F. & 48 & 2 & 114 & 109,5 & 114 & 25 & 62 & 43,5 & Com m. & Com m. & $\begin{array}{l}\text { Com Rx } \\
\text { Sem m. }\end{array}$ & $\begin{array}{l}\text { Com Rx } \\
\text { Sem m. }\end{array}$ & $\begin{array}{c}\text { sem } \\
\text { função }\end{array}$ \\
\hline C. F. P. & 49 & 2 & 95 & 96,5 & 95,5 & & & & Com m. & Com m. & Sem Rx & Sem Rx & $\begin{array}{c}\text { sem } \\
\text { função }\end{array}$ \\
\hline $\begin{array}{l}\text { M. Z. } \\
\text { C. }\end{array}$ & 50 & 2 & 102 & 108,5 & 101,5 & 30 & 12 & 21 & Com m. & Com m. & Com m. & Com m. & $\begin{array}{l}\text { supra } \\
\text { irromp. }\end{array}$ \\
\hline C. S. Z. & 51 & 2 & 136 & 136,5 & 135 & 17 & 33 & 25 & Com m. & Com m. & $\begin{array}{l}\text { Com Rx } \\
\text { Sem m. }\end{array}$ & $\begin{array}{l}\text { Com Rx } \\
\text { Sem m. }\end{array}$ & $\begin{array}{c}\text { em } \\
\text { função }\end{array}$ \\
\hline P. S. O. & 52 & 2 & 108 & 113,5 & 107 & 180 & & & $\begin{array}{l}\text { Com Rx } \\
\text { Sem m. }\end{array}$ & $\begin{array}{l}\text { Com Rx } \\
\text { Sem m. }\end{array}$ & $\begin{array}{l}\text { Com Rx } \\
\text { Sem m. }\end{array}$ & Sem Rx & - \\
\hline R. C. & 53 & 2 & 112 & 110,5 & 112 & 180 & -8 & 86 & Com m. & Com m. & $\begin{array}{l}\text { Com Rx } \\
\text { Sem m. }\end{array}$ & $\begin{array}{l}\text { Com Rx } \\
\text { Sem m. }\end{array}$ & $\begin{array}{c}\text { em } \\
\text { função }\end{array}$ \\
\hline E. B. & 54 & 2 & 118 & 111,5 & 117,5 & 44 & 39 & 41,5 & $\begin{array}{l}\text { Com Rx } \\
\text { Sem m. }\end{array}$ & $\begin{array}{l}\text { Com Rx } \\
\text { Sem m. }\end{array}$ & $\begin{array}{l}\text { Com Rx } \\
\text { Sem m. }\end{array}$ & $\begin{array}{l}\text { Com Rx } \\
\text { Sem m. }\end{array}$ & - \\
\hline $\begin{array}{l}\text { M. R. } \\
\text { M. }\end{array}$ & 55 & 2 & 110 & 109 & 109 & 22 & 40 & 31 & $\begin{array}{l}\text { Com Rx } \\
\text { Sem m. }\end{array}$ & $\begin{array}{l}\text { Com Rx } \\
\text { Sem m. }\end{array}$ & $\begin{array}{l}\text { Com Rx } \\
\text { Sem m. }\end{array}$ & $\begin{array}{l}\text { Com Rx } \\
\text { Sem m. }\end{array}$ & - \\
\hline
\end{tabular}




\section{Universidade de São Paulo Faculdade de Odontologia de Bauru \\ Al. Dr. Octávio Pinheiro Brisolla, 9-75 - Bauru-SP-CEP 17012-901 - C.P. 73 PABX (0XX14)235-8000 - FAX (0XX14)223-4679 \\ Comitê de Ética em Pesquisa}

Processo no ODON-2042002

Bauru, 25 de abril de 2002

Senhor Professor,

O projeto de pesquisa encaminhado a este Comitê de

Ética denominado "Avaliaçăo da porcentagem da presença dos terceiros molares superiores, na má oclusăo de classe II com e sem extração de pré-molares", de autoria da CD Laélia Maria Putrick que será desenvolvido sob sua orientaçăo foi enviado ao relator para avaliação.

Na reuniăo de 24 de abril, o parecer do relator, aprovando o projeto, foi aceito pelo Comitê, considerando que năo existem infraçōes éticas pendentes.

Informamos que após o envio do trabalho concluido, este comitẻ enviará o parecer final, que será utilizado para publicaçăo do trabalho.

Atenciosamente,

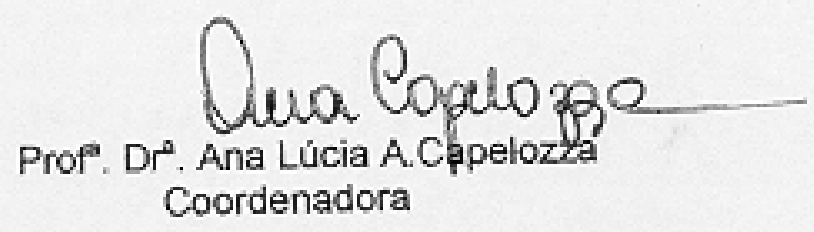

II.mo.Senhor

Prof Dr Guilherme dos Reis Pereira Janson. 


\section{Universidade de São Paulo Faculdade de Odontologia de Bauru}

Al. Dr. Octávio Pinheiro Brisolla, 9-75 - Bauru-SP - CEP 17012-901 - C.P. 73 PABX (0XX14)235-8000 - FAX (0XX14)223-4679

Comitê de Ética em Pesquiso

Processo $n^{\circ}$ ODON.2042002

Bauru, 23 de abril de 2003

Senhor Professor,

Informamos que após análise por este Comitê de Ética em Pesquisa em Seres Humanos, seu pedido de alteraçāo do título do projeto de pesquisa intitulado "Avaliaçăo da porcentagem da presença dos terceiros molares superiores, na má oclusăo de classe II com e sem extraçăo de pré-molares" de autoria da Laẻlia Maria Putrick, sob a sua orientaçāo, para "Presença clinica e angulaçăo dos terceiros molares superiores, na má oclusão de Classe II, tratada sem e com extraçōes de pré-molares superiores", foi aprovado considerando que sua metodologia năo sofreu modificaçōes.

Lembramos que após o envio do trabalho concluido, este Comitē enviará o parecer final, que serả utilizado para a publicação do trabalho.

Atenciosamente,

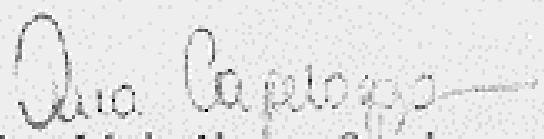

Prof ${ }^{\text {n }}$ Dr" Ana Lúcia Alvares Capelozza

Coordenadora do Comitẻ de Ética em Pesquisa em Seres Humanos 